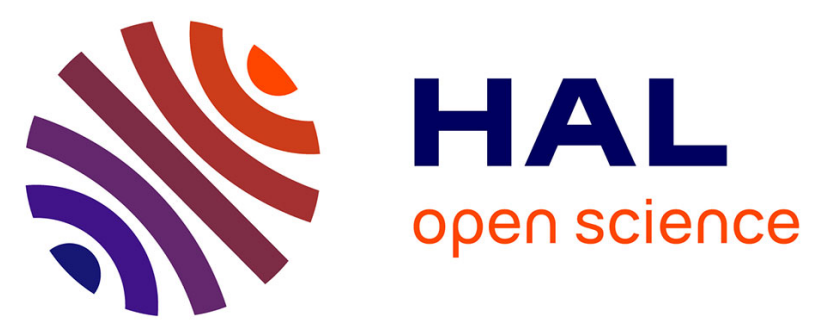

\title{
A Class of Valuable (Pro-)Activity-Based Protein Profiling Probes: Application to the Redox-Active Antiplasmodial Agent, Plasmodione
}

Bogdan Cichocki, Vrushali Khobragade, Maxime Donzel, Leandro Cotos Munoz, Stephanie Blandin, Christine Schaeffer, Sarah Cianférani, Jean Marc Strub, Mourad Elhabiri, Elisabeth Davioud-Charvet

\section{To cite this version:}

Bogdan Cichocki, Vrushali Khobragade, Maxime Donzel, Leandro Cotos Munoz, Stephanie Blandin, et al.. A Class of Valuable (Pro-)Activity-Based Protein Profiling Probes: Application to the Redox-Active Antiplasmodial Agent, Plasmodione. JACS Au, 2021, 1 (5), pp.669-689. 10.1021/jacsau.1c00025 . hal-03243960

\section{HAL Id: hal-03243960 https://hal.science/hal-03243960}

Submitted on 31 May 2021

HAL is a multi-disciplinary open access archive for the deposit and dissemination of scientific research documents, whether they are published or not. The documents may come from teaching and research institutions in France or abroad, or from public or private research centers.
L'archive ouverte pluridisciplinaire HAL, est destinée au dépôt et à la diffusion de documents scientifiques de niveau recherche, publiés ou non, émanant des établissements d'enseignement et de recherche français ou étrangers, des laboratoires publics ou privés. 


\section{A Class of Valuable (Pro-)Activity-Based Protein Profiling Probes: Application to the Redox-Active Antiplasmodial Agent, Plasmodione}

Bogdan Adam Cichocki," Vrushali Khobragade," Maxime Donzel, Leandro Cotos, Stephanie Blandin, Christine Schaeffer-Reiss, Sarah Cianférani, Jean-Marc Strub, Mourad Elhabiri, and Elisabeth Davioud-Charvet*

Cite This: JACS Au 2021, 1, 669-689

Read Online

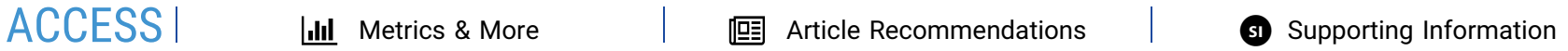

ABSTRACT: Plasmodione (PD) is a potent antimalarial redox-active drug acting at low $\mathrm{nM}$ range concentrations on different malaria parasite stages. In this study, in order to determine the precise PD protein interactome in parasites, we developed a class of (pro-)activity-based protein profiling probes (ABPP) as precursors of photoreactive benzophenone-like probes based on the skeleton of PD metabolites (PDO) generated in a cascade of redox reactions. Under UV-photoirradiation, we clearly demonstrate that benzylic oxidation of 3-benzylmenadione 11 produces the 3-benzoylmenadione probe 7, allowing investigation of the proof-of-concept of the ABPP strategy with 3benzoylmenadiones 7-10. The synthesized 3-benzoylmenadiones, probe 7 with an alkyne group or probe 9 with $-\mathrm{NO}_{2}$ in para position of the benzoyl chain, were found to be the most efficient photoreactive and clickable probes. In the presence of various $\mathrm{H}$-donor partners, the UV-irradiation of the

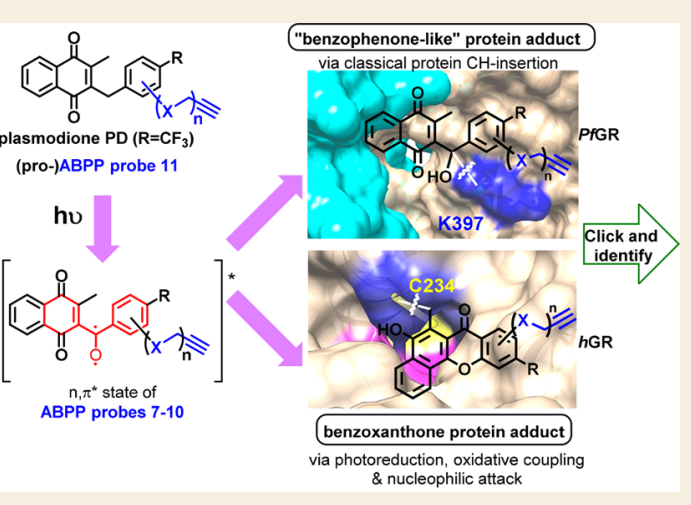
photoreactive ABPP probes generates different adducts, the expected "benzophenone-like" adducts (pathway 1) in addition to "benzoxanthone" adducts (via two other pathways, 2 and 3 ). Using both human and Plasmodium falciparum glutathione reductases, three protein ligand binding sites were identified following photolabeling with probes 7 or 9. The photoreduction of 3-benzoylmenadiones (PDO and probe 9) promoting the formation of both the corresponding benzoxanthone and the derived enone could be replaced by the glutathione reductase-catalyzed reduction step. In particular, the electrophilic character of the benzoxanthone was evidenced by its ability to alkylate heme, as a relevant event supporting the antimalarial mode of action of PD. This work provides a proof-of-principle that (pro-)ABPP probes can generate benzophenone-like metabolites enabling optimized activity-based protein profiling conditions that will be instrumental to analyze the interactome of early lead antiplasmodial 3-benzylmenadiones displaying an original and innovative mode of action.

KEYWORDS: activity-based protein profiling, antimalarial, 3-benz(o)ylmenadione, CuAAC, electrophile, photoaffinity labeling, photoredox, quinone

\section{INTRODUCTION}

To decipher drug modes of action (MoA), chemical strategies for functional proteomics have been developed in the recent years with the activity-based protein profiling ( $\mathrm{ABPP}$ ) being one of the most specific. ${ }^{1}$ This unbiased and alternative methodology to identify drug or drug metabolite interactors in diverse organisms has successfully detected protein partners of miscellaneous biomolecules ${ }^{2-4}$ (see the pioneering work from Cravatt et al. and then from Bogyo et al., with the first reports about serine hydrolase inhibitors). ABPP allows monitoring and dissecting a drug interactome from complex proteomes in their native forms. This is achieved by the design and synthesis of small drug-activity-based probes that can react with the protein targets. The selective separation of the drug-protein adducts from the whole proteome is made possible by the
$\mathrm{Cu}(\mathrm{I})$-catalyzed alkyne-azide cycloaddition (CuAAC) "click" reaction, also known as the seminal Huisgen reaction adapted for biological chemistry and proteomics purposes. 5 The $A B P P$ probe is based on three essential functional chemical elements: (1) a recognition group-drug/metabolite that has affinity to specific proteins defined as interactome; (2) a reactive group-either electrophilic or photoreactive feature that favors cross-linking or covalent binding of the probe to the

Received: January 22, 2021

Published: April 15, 2021 

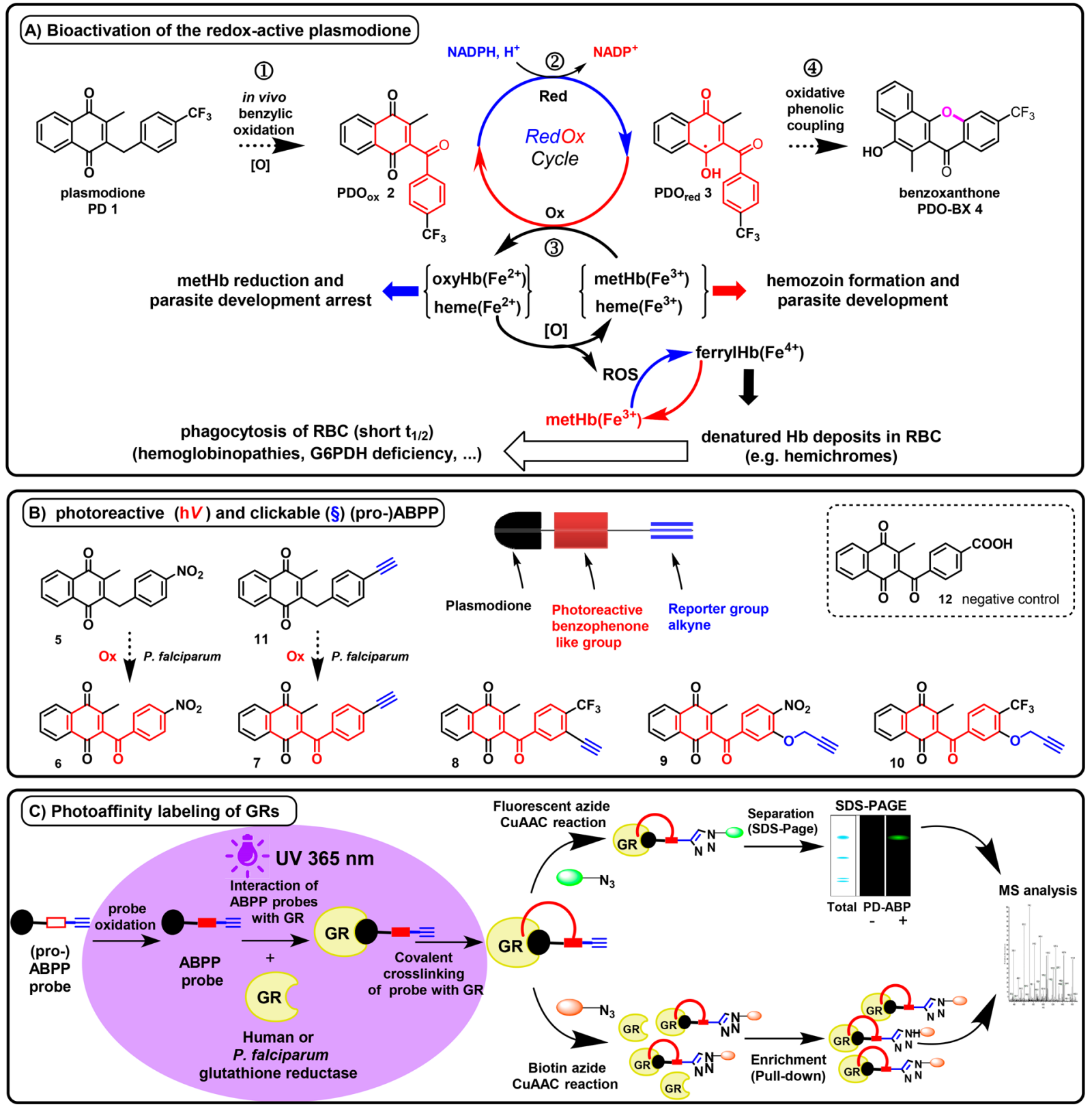

Figure 1. (A) Bioactivation of plasmodione (PD 1): Upon internalization in the parasite, plasmodione PD (1) is proposed to generate the drug metabolite $\mathbf{P D O}_{\mathrm{ox}}$ (2) by benzylic oxidation (step (1)), the 3-benzoylmenadione (benzoylMD), which, under its oxidized form, possesses a photoreactive benzophenone-like moiety (indicated in red). This metabolite is further reduced (step (2) and under its reduced form (3) takes part in oxidoreductase-mediated redox-cycling (step (3), leading to ROS-induced parasite death. In addition, the generation of a third metabolite, namely the benzo[c]xanthen-7-one (benzoxanthone, PDO-BX) derivative (4), has been envisioned as one possible metabolite generated through an oxidative phenolic coupling reaction from the 1-electron-reduced benzoylMD (3) radical (step (4). Significantly, PDO $_{\text {red }}$ (3) exists in different mesomeric species, but for the clarity of the scheme, only one species is shown. (B) Plasmodione-activity based probes (PD-ABPP): The common scaffold of the PD-ABPP probes 7-11 is a photoreactive 3-benzoylmenadione, functionalized by different electron-withdrawing groups in paraposition $\left(-\mathrm{CF}_{3}\right.$ or $-\mathrm{NO}_{2}$ or -alkyne) affecting their photoreactivity. 3-Benzylmenadiones (such as $\left.1,5,11\right)$ are not photoreactive per se, while probes 6-11 in the benzoylMD series are photoreactive. (C) ABPP strategy: This approach is aimed at identifying drug activity-based protein profiling in living parasites incubated with a parent PD-ABPP precursor designed as (pro-)PD-ABPP. The (pro-)PD-ABPP probe is released upon bioactivation through the benzylic oxidation. In this paper, our aim is to showcase the proof-of-concept by starting the work from the benzoylmenadione derivatives (metabolites and ABPP probes). Upon UV irradiation, covalent cross-linking of PD-ABP to its potential targets is expected to occur. Further, a reporter click reaction between the probe-derived alkyne and the fluorescent rhodamine azide or biotin azide reveals successful cross-linking of probe to peptides and GRs as protein models, which can be analyzed by SDS PAGE and/or LC-MS/MS. Identification of the site where the ABPP probe was bound to both GRs was investigated and discussed.

target(s); (3) a reporter group/tag (e.g., alkyne or azide) enabled to react in the click reaction with a partner (e.g., azide or alkyne) that is functionalized either by a fluorophore for visualization of the drug-protein adducts or a affinity chromatography tag for enrichment and identification of the adduct. ${ }^{7}$ An additional advantage in the ABPP field is the enlargement of the variety of chemical probes that trap representatives of various enzyme classes and can be utilized in 
proteome studies. In the case of the flavin-dependent oxidoreductase family, the design of clickable ABPP probes was limited to the cytochrome $\mathrm{P} 450,{ }^{8}$ 2-oxoglutarate oxygenases, ${ }^{9}$ and amine oxidases. ${ }^{10,11}$ According to the literature, several proteomics studies have been conducted with ABPP probes for the detection of drug targets in P. falciparum. ${ }^{12-16}$

$\mathrm{NAD}(\mathrm{P}) \mathrm{H}$-dependent flavoenzymes from the malarial parasites have been proposed as possible targets of plasmodione, an early antimalarial lead compound (PD, 3[4-(trifluoromethyl)benzyl]-menadione, 1, Figure 1). ${ }^{17}$ Initial studies have focused on the chemical reactivity of the 3benzylmenadione core, and of its key putative metabolites, the 3-benzoylmenadiones, which were shown in vitro to act as effective subversive substrates of recombinant glutathione reductases from human ( $h \mathrm{GR}$ ) and $P$. falciparum (PfGR). $\mathrm{GR}$ is a homodimeric NADPH-dependent FAD-containing enzyme (GR; EC 1.8.1.7) that belongs to the family of NADPH-dependent oxidoreductases. GR catalyzes the reduction of glutathione disulfide (GSSG): $\mathrm{NADPH}+\mathrm{H}^{+}+\mathrm{GSSG} \rightleftarrows \mathrm{NADP}^{+}+2 \mathrm{GSH}$ (eq 1). According to previous studies, suicide-substrates such as fluoro $M_{5}$, a fluoromethylmenadione derivative, inactivates GSSG reduction by $h$ GR but not naphthoquinone reduction, thus suggesting that naphtoquinone reduction occurs at a different site than GSSG reduction, possibly near the flavin, close to the NADPH binding site, as previously postulated. ${ }^{18}$

Subversive substrates inhibit GSSG reduction activity because they are reduced by the NADPH-reduced flavin enzyme species, thus preventing electrons to flow normally from NADPH to GSSG. In the presence of natural oxidizers, for example, oxygen or methemoglobin $\left(\mathrm{Fe}^{3+}\right)$ (metHb), naphthoquinone reduction was demonstrated to be reversible for PD and its key metabolite, the 3-benzoylmenadione $\left(\mathbf{P D O}_{\mathrm{ox}}\right.$, compound 2), starting a redox-cycling process (Figure 1A). Reduced benzoylmenadiones can efficiently transfer one electron to metHb, and the redox cycle constantly regenerates the benzoylmenadione under its oxidized form at the expense of the NADPH pool. ${ }^{19}$ MetHb is a critical nutrient for Plasmodium crucial for its growth (e.g., at the trophozoite stage) while $\mathrm{Hb}\left(\mathrm{Fe}^{2+}\right)$ is not digestible. ${ }^{17}$ The shift in metHb/ $\mathrm{Hb}\left(\mathrm{Fe}^{2+}\right)$ balance during redox-cycling results in metHb depletion and parasite growth arrest. From PD, the NADPH-dependent oxidoreductase-promoted redox-cycling also produces a continuous flux of reactive oxygen species (ROS) and toxic metabolites, including the reduced 3benzoylmenadione $\left(\mathbf{P D O}_{\text {red }}\right.$; compound 3$)$ (i.e., via 1-electron transfer) along with hemoglobin degradation catabolites identified as membrane-enriched hemichromes. The latter are known to act as biomarkers of red blood cell (RBC) senescence and to trigger early phagocytosis by macrophages. Hence, PD activation via PDO-mediated redox-cycling most likely results in the specific removal and clearance of the parasitized RBCs (pRBC). ${ }^{20,21}$

Furthermore, during metHb digestion, toxic heme is released into the acidic food vacuole of the parasite. To detoxify free heme, the parasite converts it into a nontoxic insoluble hemozoin biocrystal. We previously proposed that PD bioactivation in pRBCs, possibly by GR, generates a key metabolite - the benzoxanthone 4 (PDO-BX) (Figure 1A) via a cascade of redox reactions and oxidative phenolic coupling. In turn, PDO-BX can firmly interact with free heme and is thus suggested to prevent heme crystallization leading to parasite death. $^{17,20}$
Finally, in yeast, the mitochondrial type II NADPHdehydrogenase $\mathrm{Nde1}$, was found to be the main target responsible for PD redox-cycling, with GR and two other oxidoreductases (Mcr1 and Lpd1) being minor targets. ${ }^{22}$ Taken together, these observations and the current model for PD MoA suggest that, once generated, PD metabolites could (i) redox cycle with several oxidoreductases, which may vary according to parasite developmental stage, generating oxidative stress; and/or (ii) disturb key parasite processes such as hemozoin formation. Additionally, the abundance of proteins expressed in parasites is variable and depends on the parasite stages. Thus, during any ABPP study, actual drug targets expressed in traces would be difficult to distinguish from unspecific labeled but abundantly expressed proteins recovered in the HPLC MS/MS analysis. The focus of the present study was therefore to design a series of relevant and specific PD$\mathrm{ABPP}$ probes, to define standardized conditions for their use and establish a proof-of-concept of their application with isolated proteins such as $h \mathrm{GR}$ and PfGR as models (Figure 1C). Here, for the first time, we report that 3-benzylmenadiones are photoreactive and, as (pro-)activity-based protein profiling probes ((pro-)ABPP), can be used for ABPP applications.

The 3-benzoylmenadione probe generates a benzophenonelike moiety upon photoreduction, a step that mimics the reductive bioactivation drug pathway catalyzed by a flavoenzyme in the living cell.

Diversely substituted benzophenone-like and BX adducts were produced in the presence of different partners via original photoredox pathways that have not been previously described. The successful photoaffinity labeling of both GRs not only allowed the identification of naphthoquinone binding sites in GR structure but also revealed an alkylation process of the toxic heme by PDO-BX, generated upon PD redox-cycling with $h \mathrm{GR}$, which is likely a relevant event contributing to PD MoA.

\section{RESULTS AND DISCUSSION}

Design of 3-Benzoylmenadiones as Photoreactive Probes

Our original strategy for designing the PD-ABPP is leveraged from the postulated MoA of PD. ${ }^{17}$ PD was suggested to act as a prodrug generating in situ a key metabolite, PDO, upon PD bioactivation (i.e., benzylic oxidation) (Figure 1A). Interestingly, PDO possesses in its structure the 2-benzoyl-1,4naphthaledione group that could behave as a 2-benzonaphthone precursor. ${ }^{23}$ Therefore, we assumed that the redox-active PD-derived benzoylmenadione, under its reduced state, might have an intrinsic photoreactive benzophenone-like structure per se and thus permit the spontaneous covalent trapping of targets upon photoirradiation. Such probes might show high spatiotemporal control of targeted enzyme recognition/ alkylation and drastically lower nonspecific binding. Interestingly, no additional bulky photoreactive group was introduced into the PD metabolite structure. Furthermore, the newly designed ABPP probes 7-11 (Figure 1B) were functionalized in the benz(o)yl chain, by a reporter alkyne group known to bring minimal structural and electronic perturbation.

To validate the hypothesis of the intrinsic photoreactivity properties attributed to the benzophenone-like structure, we first studied the 3-benz(o)ylmenadione derivatives in model photochemical reactions. We compared the photoreactivity of the previously reported PD analogue 3-benz(o)ylmenadione 


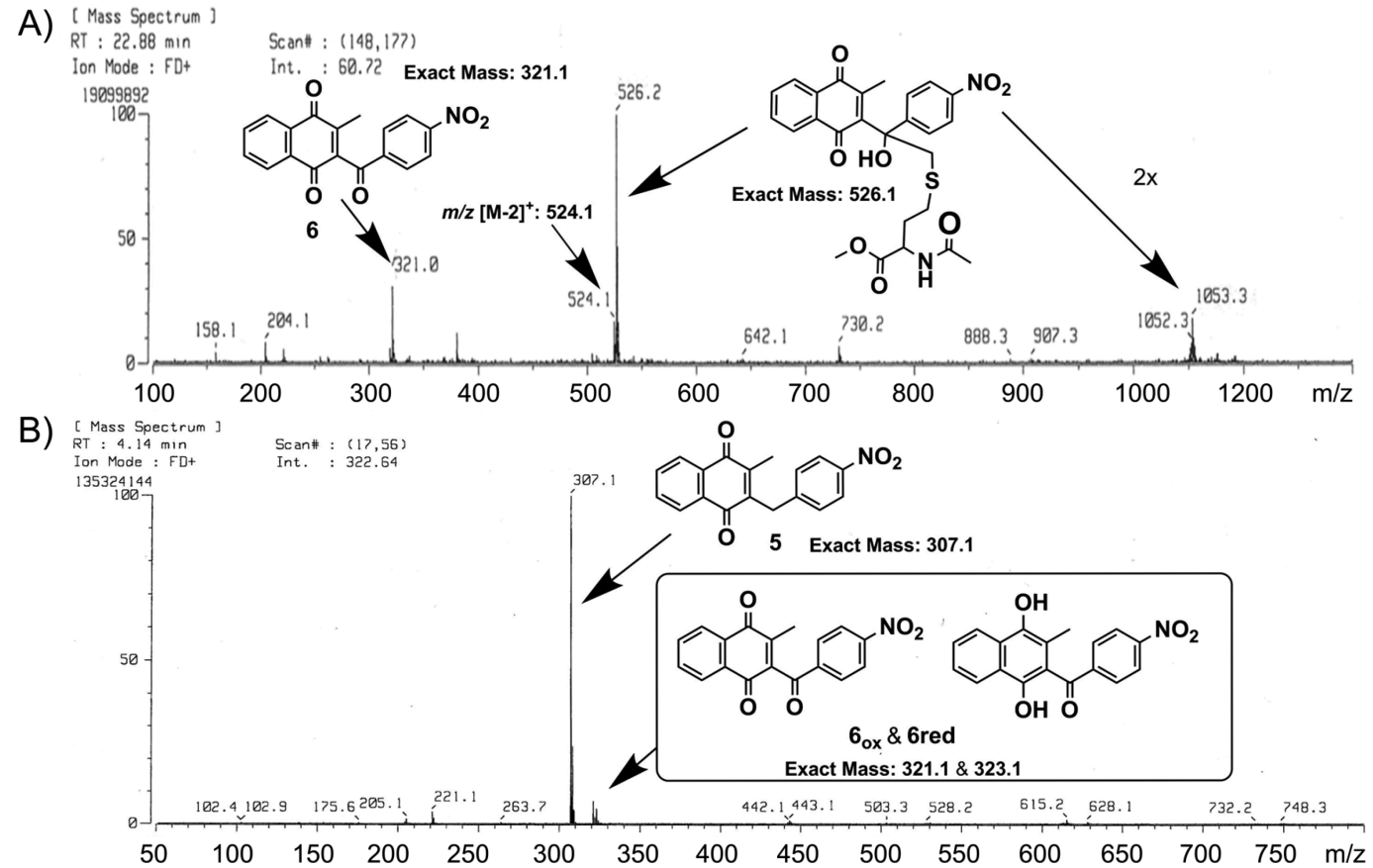

Figure 2. Mass spectrometric analysis of the photochemical reaction mixtures. Field-desorption mass spectrometry (FD-MS) analyses of the photochemical reaction mixtures of (panel A) the 3-benzoylmenadione 6 or (panel B) the 3-benzylmenadione 5 derivatives, in the presence of the diprotected methionine nMet.

Scheme 1. Synthesis of the 3-Benzoylmenadiones 7-10 (Paths A and B) through the Friedel-Crafts Reaction Variant ${ }^{31}$ and the 3-Benzylmenadione 11 (Path $\mathrm{C}$ ) through the Kochi-Anderson Reaction ${ }^{32, a}$

Starting materials:

A.

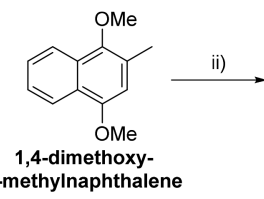

B.

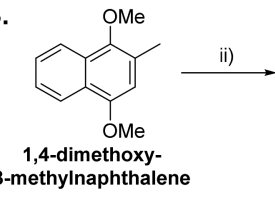

C.<smiles>CC1=CC(=O)C(=O)c2ccccc2C1=O</smiles>

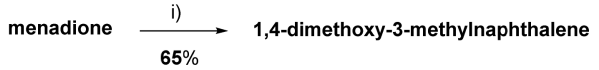<smiles>[R]c1ccc(C(=O)c2c(C)c(OC)c3ccccc3c2OC)cc1[R]</smiles><smiles>[R]c1ccc(C(=O)c2c(C)c(OC)c3ccccc3c2OC)cc1[R]</smiles>

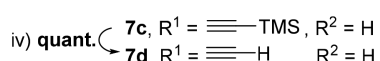
iv) $85 \% \quad 8 \mathrm{cc}, \mathrm{R}^{1}=\mathrm{CF}_{3}, \mathrm{R}^{2}=\stackrel{\mathrm{R}^{2}=H}{=} \mathrm{TMS}$

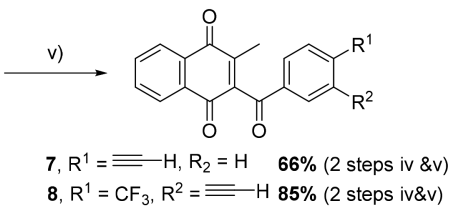

7b, $R^{1}=I, R^{2}=H, 47 \%$ $8 b, R^{1}=C_{3}, R^{2}=1,66 \%$ $8 d, R^{1}=C_{3}, R^{2}=\equiv H$
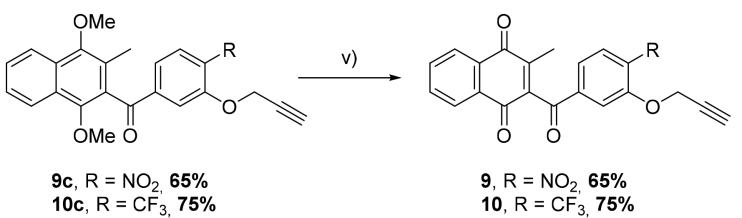
$9 \mathrm{~b}, \mathrm{R}=\mathrm{NO}_{2}, 82 \%$
$10 \mathrm{~b}, \mathrm{R}=\mathrm{CF}_{3}, 67 \%$<smiles>CC1=C(Cc2ccc(I)cc2)C(=O)c2ccccc2C1=O</smiles>

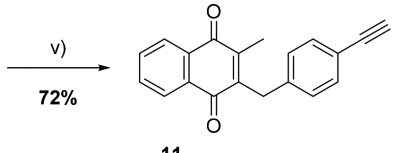

11 iii) $90 \%(11 \mathrm{~b}, \mathrm{R}=1$

iv) $97 \% C \begin{aligned} & 11 \mathrm{c}, \mathrm{R}= \\ & 11 \mathrm{~d}, \mathrm{R}=\mathrm{\equiv} \mathrm{T} \mathrm{H}\end{aligned}$

${ }^{a}$ Reaction conditions: (i) 1. SnCI 2 cc HCI, EtOH, rt, 2 h, 2. $\mathrm{Me}_{2} \mathrm{SO}_{4}$ acetone, $\mathrm{KOH}, \mathrm{MeOH}, 60{ }^{\circ} \mathrm{C}$, 4 h; (ii) TfOH/TFAA, DCM, and A. 4iodobenzoic acid 7a, or 3-iodo-4-(trifluoromethyl)benzoic acid 8a, B. 4-nitro-3-fluorobenzoic acid 9a, or 3-fluoro-4-(trifluoromethyl)benzoic acid 10a, $0{ }^{\circ} \mathrm{C}$ then rt, $16 \mathrm{~h}$; (iii) Cul, $\mathrm{Pd}\left(\mathrm{PPh}_{3}\right)_{2} \mathrm{CI}_{2} \mathrm{NEt}_{3} \mathrm{rt}, 16 \mathrm{~h}, \mathrm{HC} \equiv \mathrm{C}$-TMS; (iv) TBAF, THF, rt, $1.5 \mathrm{~h}$; (v) CAN, $\mathrm{H}_{2} \mathrm{O} / \mathrm{MeCN}, \mathrm{rt}, 3 \mathrm{~h}$; (vi) $\mathrm{K}_{2} \mathrm{CO}_{3} \mathrm{DMF}$, propargylic alcohol, $60^{\circ} \mathrm{C}, 24 \mathrm{~h}$; (vii) 4-iodophenylacetic acid, $\mathrm{AgNO}_{3} \mathrm{Na}_{2} \mathrm{~S}_{2} \mathrm{O}_{8} \mathrm{MeCN} / \mathrm{H}_{2} \mathrm{O}$, reflux, $4 \mathrm{~h}$.

5-6 pair $^{17}$ (Figure 1B) upon photoirradiation at $350 \mathrm{~nm}$ (Figure 2) in comparison with benzophenone (Figure S1) to evaluate whether the keto group of the benzoyl chain is essential for photoreaction. For this, we used $N$-acetylmethionine methyl ester ( $\mathrm{N}$-Ac-Met-OMe, shortened as $\mathrm{nMet}$ ) as a partner model, in accordance with previous studies demonstrating that methionine and its $\mathrm{N}$-Ac-Met-OMe derivative are predominantly alkylated at the side-chain in $\alpha$ position to the sulfur. ${ }^{24,25}$ The products of the photoreaction were analyzed by field desorption-mass spectrometry (FDMS). As observed in Figure 2A, the insertion product of the 3benzoylmenadione derivative 6 and nMet displayed a mass 
peak at $m / z=526.2$. Under the same photoirradiation conditions, the photoreactive benzophenone generated the insertion product with nMet as attested by the presence of mass peaks at $m / z=387.2\left(\mathrm{M}^{+}\right)$and $369.2\left(\mathrm{M}^{+}-\mathrm{H}_{2} \mathrm{O}\right.$ ) (Figure $\mathrm{S} 1)$. No major insertion product was observed for the 3benzylmenadione derivative 5 (Figure $2 \mathrm{~B}$ ), demonstrating that the 3-benzoyl chain is essential for the photoreactivity of the benzoylmenadione derivative 6 .

Interestingly, probe 6 appears to be photochemically reactive per se, even in the absence of a prereduction step in the presence of the NADPH/GR. The 3-benzoyl-dihydronaphthoquinone is likely generated by photoreduction upon photoirradiation, ${ }^{23,26}$ thus allowing formation of the insertion product. At first glance, we neglected the small peaks appearing at $m / z=321.1$ and 323.1 suggesting the formation of trace photoproducts upon photoirradiation of the 3-benzylmenadione 5, which were finally attributed to both oxidized and reduced species of the 3-benzoylmenadione 6 (Figure 2, black box). This observation was confirmed later when we used the most photoreactive 3-benzylmenadione ABPP probe $\mathbf{1 1}$ per se to investigate the generation of photoproducts upon UVphotoirradiation.

Using FD-MS under the same experimental conditions with 3-benzoylmenadiones, we were able to observe the insertion product of the benzoylmenadione $\mathbf{6}$ with a $p$-nitro-benzoyl derivative but not with benzoylmenadione 12 with a carboxylic acid group in para- to the benzoyl ring (data not shown). This result might be explained by the fact that the carboxylate form, which predominates in neutral aqueous solution, is not an electron-withdrawing group (EWG) but rather a donor or even neutral ${ }^{27}$ group; some photochemical decarboxylations were also reported. ${ }^{28}$ Thus, the promising photochemical properties of probe 6 convinced us to design the new PD-ABPP probes 7-11 (Figure 1B) functionalized by different EWGs in paraposition of the benz(o)yl chain and an additional reporter group (i.e., alkyne prone to be reactive with azides in the click reaction). Noteworthy is that the $p$-alkyne group can be considered both as the reporter group for the CuAAC reaction but also an EWG to favor the formation of an insertion product upon photoirradiation. ${ }^{29,30}$

Synthesis of Clickable 3-Benz(o)ylmenadiones as PD-ABPP Probes

Each of the 3-benzoylmenadiones alkyne derivatives 2, 4, 6, and $\mathbf{8}$ was synthesized using as a key step, the Friedel-Crafts acylation, recently described by our team. ${ }^{31}$ Using the electronrich 1,4-dimethoxy-2-methylnaphthalene (i.e., aromatic nucleophile) and readily available synthetic benzoic acids $(7 \mathbf{a}-10 a)$ (i.e., acylating agent) as starting materials, this reaction variant allowed us to prepare the corresponding 2-benzoyl-1,4dimethoxynaphthalene intermediates $(\mathbf{7 b}-\mathbf{1 0 b})$ in mild conditions. These are key intermediates, to achieve, in a few additional steps the desired chemicals probes described in paths A and B (Scheme 1). The four benzoyl-1,4-dimethoxy-2methylnaphthalenes $7 \mathbf{b}-10 b$ were obtained with $47 \%$, 66\%, $82 \%$ and $67 \%$ yield, respectively. It is worth mentioning that without the Friedel-Crafts reaction variant, the 3-benzoylmenadiones functionalized by an alkyne group could not have been produced easily (i.e., see the different synthetic pathways discussed previously). ${ }^{31}$

A Sonogashira pallado-catalyzed coupling allowed the trimethylsilane (TMS)-protected alkyne insertion, starting from the iodinated aromatic compounds $\mathbf{7 b}-\mathbf{8 b}$, to obtain efficiently intermediates $\mathbf{7 c - 8 c}$. These were successively deprotected in $\mathbf{7 d}-\mathbf{8 d}$, first with TBAF and then by cerium ammonium nitrate (CAN) to afford both desired alkynated 3benzoylmenadiones $\mathbf{7 - 8}$ upon oxidative demethylation. For the synthesis of alkynes $9 \mathrm{c}$ and 10c, propargyl alcohol was first submitted to a nucleophilic aromatic substitution reaction on the electron-poor fluorinated aromatic intermediates $\mathbf{9 b}$ and $\mathbf{1 0 b}$, leading to the targeted quinones $\mathbf{9}$ and $\mathbf{1 0}$ after oxidative demethylation with CAN.

$A B P P$ probe $\mathbf{1 1}$ in the benzylmenadione series was synthesized according to path $\mathrm{C}$ in a five-step route starting from the Kochi-Anderson reaction ${ }^{32}$ (Scheme 1). First, 3benzylmenadione 11a ( $80 \%)$ was produced by addition to menadione of a benzyl radical generated from 4-iodophenylacetic acid by decarboxylation in the presence of silver salts' catalysis and stoichiometric amounts of the $\mathrm{Na}_{2} \mathrm{~S}_{2} \mathrm{O}_{8}$ oxidant. Owing to the incompatibility of the methyl group of 11a in basic medium, it was not possible to introduce the alkyne moiety directly on the quinone by palladium cross coupling reaction. Consequently, the benzylmenadione 11a was first reduced with $\mathrm{SnCl}_{2}$ in acid medium to the corresponding 2-(4iodobenzyl)-3-methylnaphthalene-1,4-diol intermediate, which was protected (after a quick crystallization step under nitrogen) by methylation using dimethylsulfate to produce the 2-(4-iodobenzyl)-1,4-dimethoxy-3-methylnaphthalene intermediate $11 \mathbf{b}(56 \%)$. Then, the iodo derivative $11 \mathbf{b}$ was submitted to the Sonogashira pallado-cross coupling reaction, using ethynyl(trimethyl)silane in excess. This reaction successfully promoted the formation of the TMS-protected alkyne 11c in excellent yield (90\%). The TMS group was removed from 11c by TBAF to obtain the free terminal alkyne 11d (97\%), and the 1,4-quinone moiety was recovered by oxidative demethylation following addition of CAN in acetonitrile $(\mathrm{ACN}) /$ water mixture to obtain in good yield (66\%) the targeted 3-benzyl-[4'-alkynyl]-menadione 11.

Standardization of the UV Cross-Linking Parameters Using PD-ABPP Probes and nMet as Partner Model

These PD-ABPP probes have been primarily designed to highlight both the binding sites and elucidate the protein interactome of PD in living cells. Additionally, considering the originally studied glutathione reductases from the pRBC unit, the reduction site of subversive substrates is a matter of debate (discussed in ref. ${ }^{33}$ ), even if menadione was observed to bind to various cavities of the crystal structure of the human enzyme. $^{34}$ Before testing the cross-linking ability of these ABPP probes, we undertook the evaluation of their inhibition capabilities with the human GR in $1 \mathrm{mM}$ GSSG reduction assays (in $2 \% \mathrm{ACN}$ instead of $1 \% \mathrm{DMSO}$ ). We observed that the probes $7, \mathbf{8}, \mathbf{9}$, and 10 behaved as potent GR inhibitors, with $\mathrm{IC}_{50}$ values of $0.60,0.80,0.58$, and $0.85 \mu \mathrm{M}$, respectively; these values are in the same range as those previously observed for 6 and 12 (0.4 and $0.7 \mu \mathrm{M}$, respectively). ${ }^{17}$ Thus, functionalization did not decrease the inhibitor activity in comparison to effective 3-benzoylmenadiones.

Photoreactivity of the PD-ABPPs was evaluated under the same photoreaction conditions used for the model reaction between nMet and probe 6 (vide supra). We observed that among the five $\mathrm{PD}-\mathrm{ABPP}$, the photoreaction preferably occurred with probes 6,7 , and 9 bearing $-\mathrm{NO}_{2}$ or alkyne (strong to moderate EWG) in para-position in accordance with yields of starting probe consumption and photoproduct formation, calculated from the ${ }^{1} \mathrm{H}$ NMR spectra (Table 1, 
Table 1. Photoirradiation of $\mathrm{N}$-Acetyl Methionine Acid Methyl Ester (nMet) and Probes 6, 7, and $9^{a}$

$\begin{array}{ccc}\begin{array}{c}\delta(\mathrm{ppm}) / \text { signal shape for each probe and } \\ \text { photogenerated product from } \\ \text { spectra }\end{array} & \begin{array}{c}\text { residual } \\ \text { probe:formed } \\ \text { products (ratio) }\end{array} \\ 6 & 8.07(\mathrm{dd}) / 8.04(\mathrm{dd}) & 69: 31 \\ 7 & 7.60(\mathrm{dd}) / 7.38(\mathrm{dd}) & 75: 25 \\ 9 & 7.51(\mathrm{dd}) / 7.40(\mathrm{dd}) & 61: 39\end{array}$

${ }^{a}$ Ratio of residual probe and formed coupling products is based on the integration of the corresponding signal in the ${ }^{1} \mathrm{H}$ NMR spectra of the crude reaction mixtures.

Figures S2-S4). For probes 8, 10, and benzophenone, the ${ }^{1} \mathrm{H}$ NMR data did not allow the calculation of the yields of probe consumption or formed products because the signals were either too small or combined with other signals. The $\mathrm{CF}_{3}$ group is known to be a strong EWG group, such as $-\mathrm{NO}_{2}$ and even more than an alkyne group ${ }^{27}$ but the mesomeric effect, inherent to both of the latter groups, can stabilize more efficiently a ketyl radical generated by photoreduction, than the inductive effect of a $-\mathrm{CF}_{3}$ group. Additionally, we determined the absorption spectrophotometric characteristics $\left(\varepsilon^{\max }\right.$ and $\lambda^{\max }$ ) of all PD-ABPP probes 7-11 along with probe $\mathbf{6}$ (Figure $\mathrm{S} 5$; at the photoirradiation $\lambda$ of $350 \mathrm{~nm}$, all the PD-ABPP probes are characterized by weak $n-\pi^{*}$ transitions). On the basis of these data, we can conclude that benzoylmenadione probes are photoreactive per se and can be used to covalently trap targets in an ABPP approach.

The (Pro-)ABPP Benzylmenadione Probe 11 Generates the Benzoylmenadione 7 upon Photoreduction and Then

\section{Oxidation}

Starting from the prior observation of the generation of trace amounts of oxidized and reduced benzoylmenadione species upon photoirradiation of the parent 3-benzylmenadione, we investigated the reaction to produce the most efficient photoreactive probe 7 from the parent prodrug, the 3benzylmenadione 11. Since it is well-known that the dihydronaphthoquinone is favorably generated via the semiquinone by photoreduction of the naphthoquinone in isopropanol, ${ }^{35}$ we submitted the benzylmenadione probe $\mathbf{1 1}$ to UV-irradiation in this solvent under bubbling of oxygen. After $72 \mathrm{~h}$ of irradiation, the formation of the corresponding 3benzoylmenadione was clearly observed, as attested, for example, by monitoring the deshielding of the alkyne proton seen in the NMR spectra (Figures 3, S6, for the full-scale ${ }^{1} \mathrm{H}$ NMR spectrum). The same reaction in a 1:1 mixture of ACN and water only afforded traces of the species oxidized at the benzylic position. To overcome the poor solubility of probe $\mathbf{1 1}$ in both systems, a 1:1 mixture of dichloromethane and isopropanol was selected, and these conditions were shown to be optimal with a full conversion of the initial 3benzylmenadione $\mathbf{1 1}$ to the 3-benzoylmenadione 7 upon photoirradiation. The aerobic benzylic oxidation mechanism likely involves intermediate hydroperoxidation. ${ }^{36}$ However, the low quantity of 3-benzoylmenadione generated during the photoirradiation of 3-benzylmenadione in an $\mathrm{ACN} /$ water mixture prevented any detailed study on the optimization of the conditions for effective photoalkylation followed by the click reaction. This condition is not physiological, but we could demonstrate herein that naphthoquinone reduction by a flavoenzyme (e.g., both GRs) can be substituted by UVphotoactivation in the presence of oxygen. Notably, the

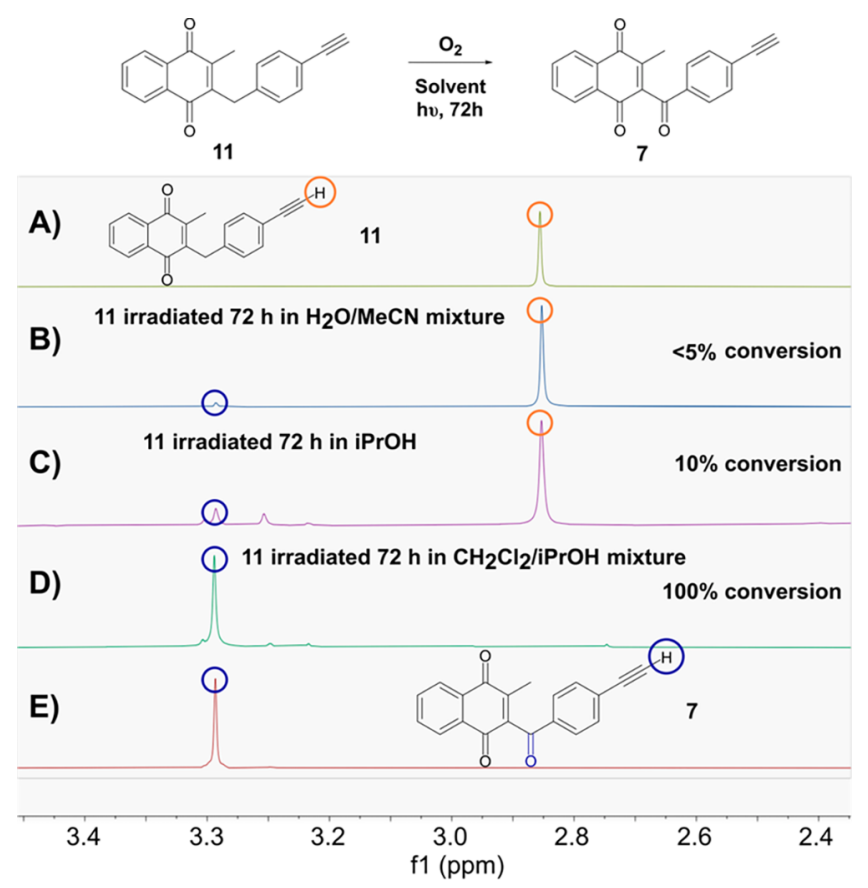

Figure 3. Overlay of the ${ }^{1} \mathrm{H}$ NMR spectra in the $2.8-3.4 \mathrm{ppm}$ area of (A) pure probe 11 and reaction mixtures of 3-benzylmenadione probe 11 in various solvents after $72 \mathrm{~h}$ of UV-photoirradiation at $350 \mathrm{~nm}$ : (B) in a 1:1 $\mathrm{H}_{2} \mathrm{O}: \mathrm{MeCN}$ system; (C) in $\mathrm{iPrOH}$; (D) in a $1: 1$ $\mathrm{CH}_{2} \mathrm{Cl}_{2}: \mathrm{iPrOH}$ system; (E) pure 3-benzoylmenadione probe 7 .

benzylic oxidation might occur in living cells during enzymic catalysis with flavoenzymes in a hydrophobic environment like membrane lipid bilayers or a hydrophobic protein core. For this reason, the following study was carried out using 3benzoylmenadione-based ABPP probes (instead of 3-benzylmenadione-based ABPP probes) to optimize the methodology and strengthen the ABPP approach.

\section{Characterization of Clickability Properties of the ABPP Probes Using Azide Models}

The click (CuAAC) reaction is crucial for the analysis of complex proteomes because it allows the grafting of a pulldown-tag to the cross-link adducts. Subsequent adduct enrichment through the affinity purification enhances correct peptide identification during MS analysis. The ABPP probes 7-10 were predicted to have different click reaction reactivity depending on the position of the alkyne on the phenyl ring and the length of the linker connecting them (via $\mathrm{O}-\mathrm{CH}_{2}$ or directly attached). To assess the influence of both factors on the ABPP properties and select the best probe in model click reactions, we first evaluated the $\mathrm{PD}-\mathrm{ABPP}$ s reactivity with the commercially available and fluorescent rhodamine azide (RA) (Figure S7C). RA was used to develop and improve the reaction conditions by varying $\mathrm{Cu}(\mathrm{I})$ ligands (TBTA, THPTA, or BCDA) and/or the reductants (NaASc and TCEP) that are essential for the efficiency of the $\mathrm{CuAAC}$ reaction (Figure $S 7 A, B)$. The yields of the CuAAC reactions were determined by LC-MS analysis (Figures S8-S15).

During the development of an optimized protocol for the click reaction, we identified several factors, which surprisingly have greater than anticipated influence on the effectiveness of the click reaction with ABPP probes 7-10. Although wellknown, the influence of these factors has not been sufficiently emphasized and described in the literature and has led us to 

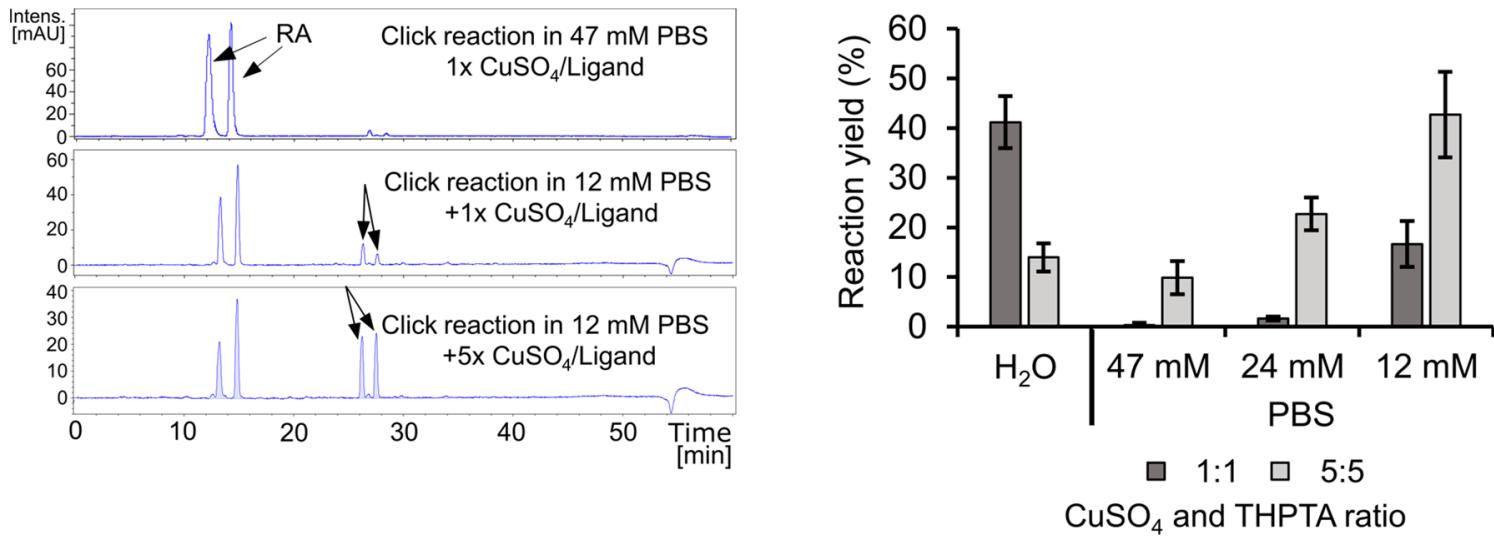

Figure 4. Phosphate buffer affects the click reaction efficiency. An increase of $\mathrm{CuSO}_{4}$ and THPTA ratios and decrease of PBS concentrations led to a click reaction between probe 7 and RA as efficient as in pure water. Left panel: overnight click reaction of RA with probe 7 in $47 \mathrm{mM}$ or $12 \mathrm{mM}$ phosphate buffer. Copper-ligand preincubated mixture was added after $40 \mathrm{~min}$ of incubation. Copper-ligand preincubation mixture $-1: 1=132 \mu \mathrm{M}$ of TCEP, $\mathrm{CuSO}_{4}$, and THPTA; 5:5 $=132 \mu \mathrm{M}$ of TCEP and $660 \mu \mathrm{M}$ of $\mathrm{CuSO}_{4}$ and THPTA. Chromatograms using absorption detection at 507 $\mathrm{nm}$ are shown. The two peaks evidenced for RA are related to both isomers in solution. Right panel: Yields of reactions determined from reactions in left panel; additional reaction data in $\mathrm{H}_{2} \mathrm{O}$ and $24 \mathrm{mM} \mathrm{PBS}$ are shown. Reactions were analyzed by LC-MS. Total area of rhodamine absorption at $507 \mathrm{~nm}$ of the peaks corresponding to the product mass was measured and normalized to $24 \mu \mathrm{M}$ RA unreacted control. $N=3$ independent experiments Error bars represent $\pm \mathrm{SD}$.
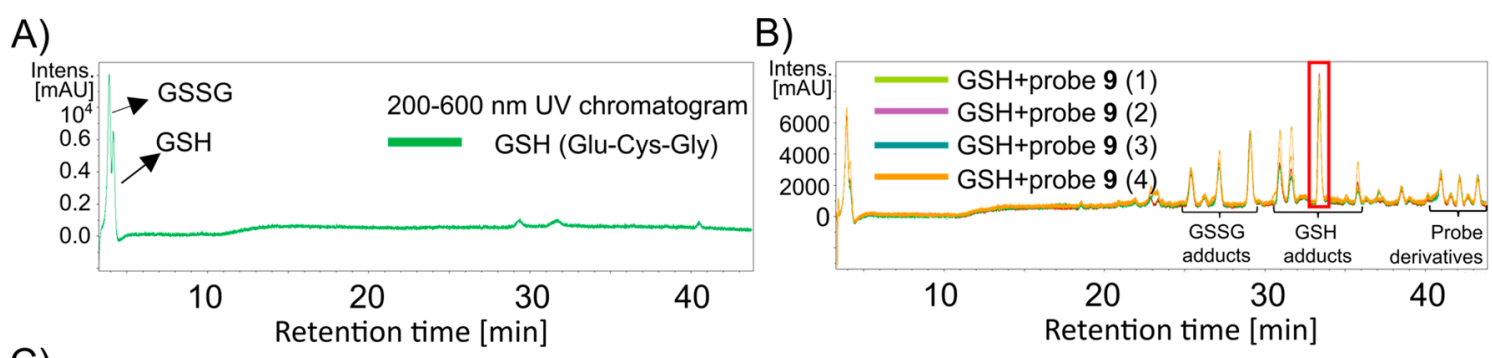

C)
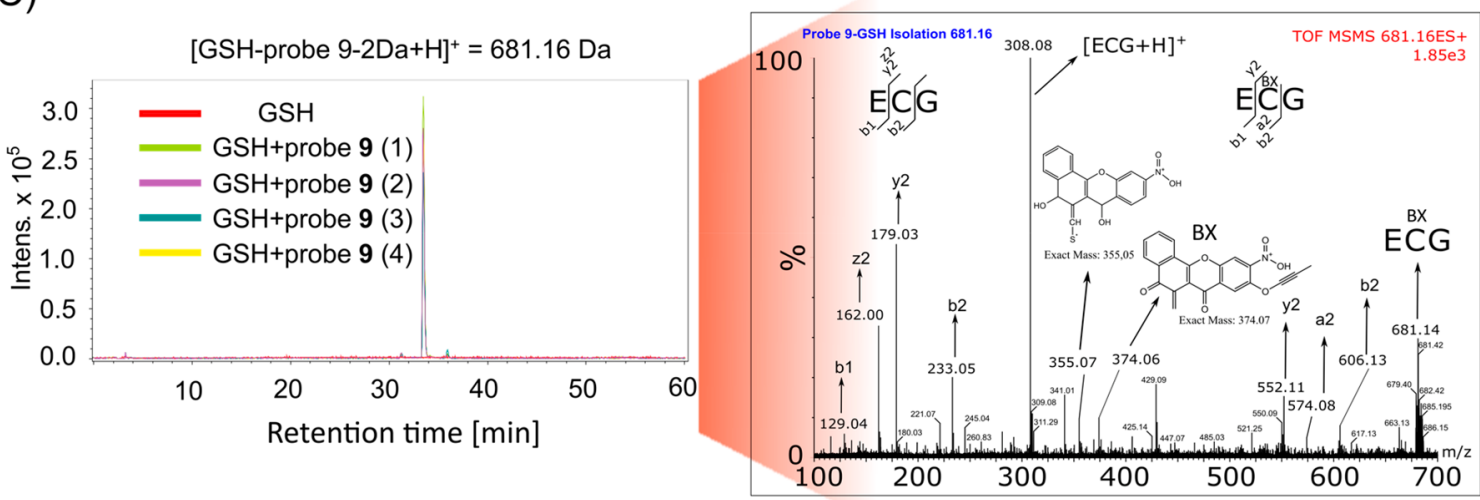

Figure 5. Probe 9 forms photoadducts with GSH in aqueous ACN conditions. (A) Chromatogram using absorption detection at $200-600 \mathrm{~nm}$ obtained by LC-MS analysis of reaction mixture containing GSH $(3 \mathrm{mM})$ without ABPP probe upon 8 min UV irradiation. Glutathione disulfide (GSSG, RT $=4 \mathrm{~min}$ ) is formed in the reaction by oxidation of GSH (RT = 4.25). (B) Under the conditions described in (A), 200-600 nm chromatogram is depicted after LC-MS analysis of reaction mixture containing probe $9(600 \mu \mathrm{M})$ and $3 \mathrm{mM}$ GSH upon UV irradiation for 8 min $(n=4)$. Multiple peaks corresponding to different GSH and GSSG adducts (different cross-linking site, GSH and GSSG fragments, double crosslinking) are visible in the chromatograms. Peak corresponding to mass of photo-cross-linked adduct of full GSH and probe 9 is highlighted in red box $(\mathrm{RT}=33.5 \mathrm{~min})$. (C) Left panel - Extracted ion chromatogram of $m / z=618.16 \mathrm{Da}$ from reaction in (B). Right panel - Fragmentation pattern of the selected peak in (B) spectrum showing adduct $m / z$ at $681.16 \mathrm{Da}$. ECG - amino acid letter code of GSH. Peaks on the right side from $m / z=308.08$ originate from probe 9-derived BX-SG fragmentation, on the left side from GSH fragmentation.

carry out a detailed fundamental investigation of each of the partners of the CuAAC reaction (vide infra). Additional observations, troubleshooting and click reaction optimization steps are described in the Supporting Information.

To improve the performance of the CuAAC reaction, we applied the generally used $\mathrm{CuSO}_{4}$-THPTA-TCEP (copper source-ligand-reductant) trio in a 1:1:1 ratio. According to the yield of the optimized click reaction (Figure S10B), the sequence of probe efficiency (i.e., $2 \mathrm{~h}$ reaction) was determined as follows: probe 7 with -p-alkyne $(58.8 \%$ yield $)>$ probe 9 with $-p-\mathrm{NO}_{2}$ and $m-\mathrm{O}-\mathrm{CH}_{2}$-alkyne $(12.8 \%$ yield $)>$ probe $\mathbf{1 0}$ with $-p-\mathrm{CF}_{3}$ and $m-\mathrm{O}-\mathrm{CH}_{2}$-alkyne $(2.9 \%$ yield $)>$ probe 8 with $-p-\mathrm{CF}_{3}$ and $m$-alkyne $(2.2 \%$ yield $)$. The CuAAC reaction efficiency can be directly correlated with the probe structure 
Scheme 2. Chemical Analysis of the Insertion Products upon Photoirradiation of the ABPP Probe 9 with Glutathione (GSH) by Mass Spectrometry ${ }^{a}$
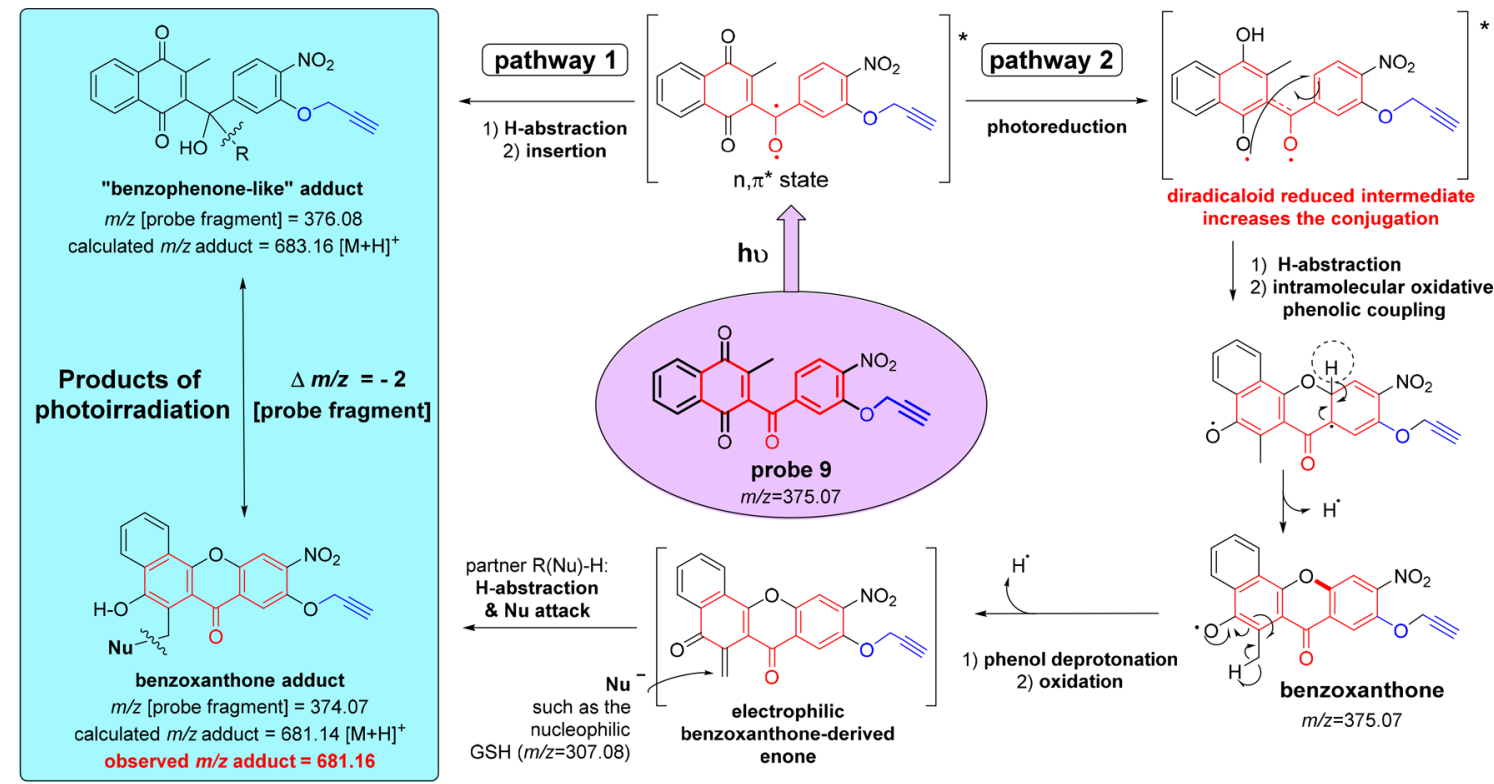

${ }^{a}$ Two pathways of photoreactivity of the benzoylmenadione were expressed through the formation of two insertion products (blue box) with nucleophilic partners.

and the resulting three factors: steric effects around the alkyne group, aqueous solubility of the probe and EWG properties of the aryl side groups (See Supporting Information, section "Click reaction optimization and troubleshooting").

Additionally, in a click reaction with probe 7 , we compared the generally used THPTA ligand with another $\mathrm{Cu}(\mathrm{I})$ ligand, the bathocuproinedisulfonic acid (BCDA) ${ }^{37}$ in various conditions of the (copper source-ligand-reductant) trio both in water and in PBS buffer (Tables S1 and S2).

With this optimization study, we could conclude that phosphate ions can inhibit the CuAAC reaction and that this problem can be solved by lowering the phosphate buffer concentration and increasing copper/ligand ratio with respect to TCEP (Figure 4). Under these newly designed experimental conditions, we demonstrated that probe 7 can be clicked with an efficiency as high as in water without increasing concentrations of the reductant. BCDA is fully compatible with this click reaction conditions in PBS buffer (Table S2, R28-R30). Furthermore, it is preferred over THPTA in oxygen-free conditions. ${ }^{38}$

Finally, we analyzed the click reaction of probe 7 with biotin-azide (BA), which is used to enrich tagged adducts by interaction with streptavidin. Despite changing the cosolvent of the reaction medium from DMF to $\mathrm{ACN}$, the $\mathrm{Cu}(\mathrm{I})$ cycloaddition of BA had a similar pattern in triazole formation efficiency as RA (R32-39 vs R40-48; Tables S3 and S4). Thus, we conclude that our optimized click conditions are also compatible with an efficient labeling of alkynes with the biotin tag.

\section{Using Peptide as a Model for Photoreaction}

Based on nMet-PD-ABPP cross-linking data, we chose probes 7 and 9 to further explore the cross-linking ability of the ABPPs toward a peptide model. Additionally, this allowed us to determine the peptide adduct behavior (mass shift, fragmentation) during MS analysis, which is a crucial parameter to facilitate detection in proteomic analysis. The
GSH and P52C peptides were chosen as models for crosslinking. GSH was selected as a model peptide because of its commercial availability, simple structure, high solubility in water, and relevance in the context of our model approach. P52C is a 16 amino-acid-peptide covering the pseudoactive site of the trypanothione disulfide oxidoreductase from T. cruzi. ${ }^{39}$

To assess the photoactivation of ABPPs in more physiological conditions, cross-linking with GSH or P52C was performed in a water:organic solvent mixture $\left(\mathrm{H}_{2} \mathrm{O}: \mathrm{ACN}\right.$, $1: 1, \mathrm{v} / \mathrm{v})$. These conditions were different from those used for the cross-linking conditions with nMet (vide supra) where pure ACN solvent was used. However, we observed that the probe solubility is significantly limited in aqueous ACN solutions (Figure S16). The observed solubility properties of the probes followed this sequence (from the less to the most soluble): probe $10<$ probe $8 \approx$ probe $7<$ probe 9 . Since probe 9 was the most water-soluble ABPP probe and displayed the highest cross-linking efficiency with nMet, we used it as a binding partner for GSH. We found that although reagent concentrations were lowered (from $\mathrm{mM}$ to $\mu \mathrm{M}$ ), we were still able to identify a significant fraction of GSH/GSSG-probe adducts after overnight photoirradiation (Figure 5A,B).

MS/MS analysis of the most prominent product $(681.16 \mathrm{Da}$, retention time $(\mathrm{RT})=33.5 \mathrm{~min})$ revealed that this adduct has apparently lost two hydrogens (expected $\mathrm{M}-2 \mathrm{H}$ ) compared with the initially expected mass of the photoalkylated peptide (Scheme 2, pathway 1). However, MS fragmentation of this adduct revealed no further alteration from predicted peptide fragmentation patterns (Figure 5C). Similarly, cross-link adducts have been detected for P52C (Figure S17).

A more rational explanation for the apparent loss of two hydrogen atoms of the observed probe 9-GSH adduct could stem from the second pathway (Scheme 2) upon photoirradiation of probe 9 in the presence of GSH. After photoreduction, an intramolecular process, much faster because it is entropically favored, leads to the benzoxanthone 
A)

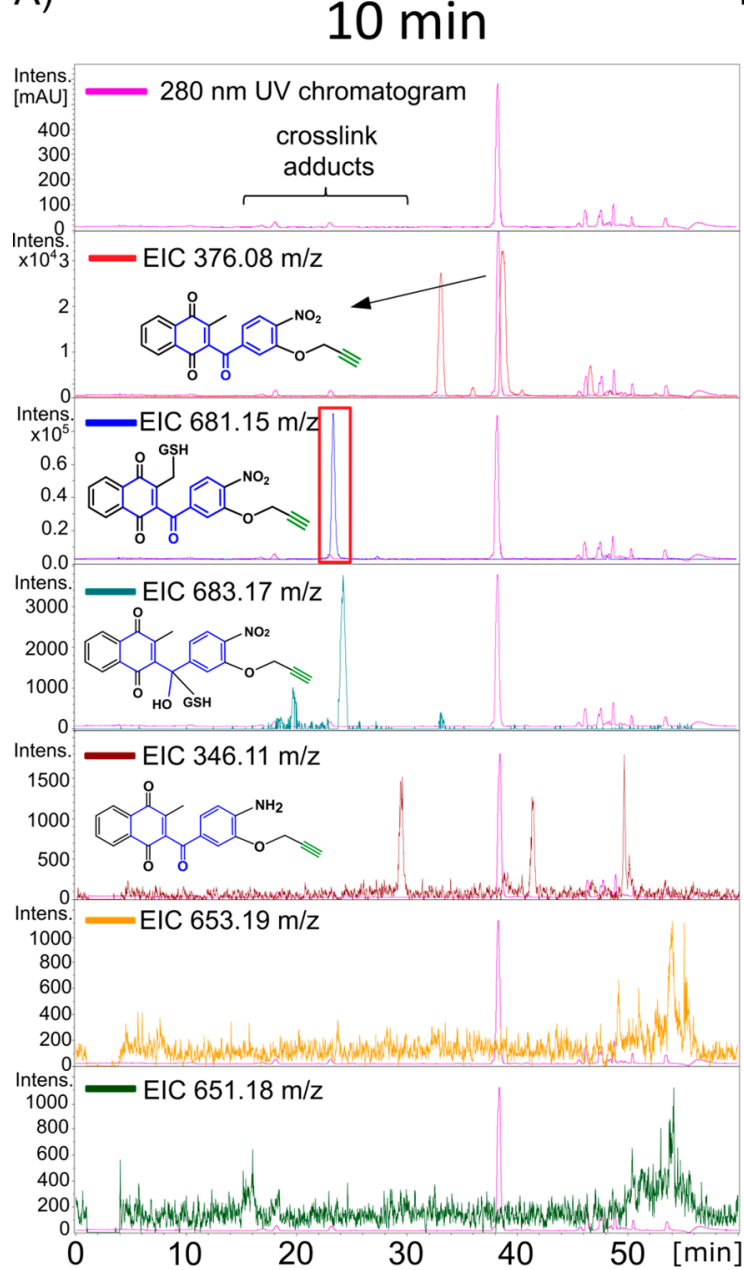

C)

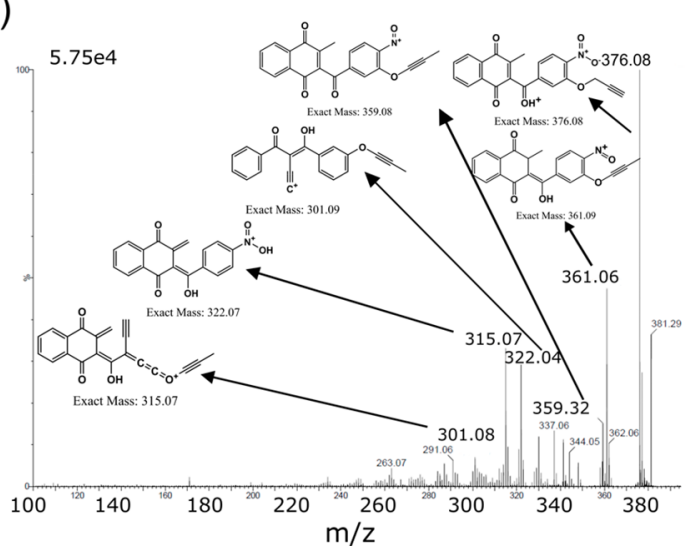

B)

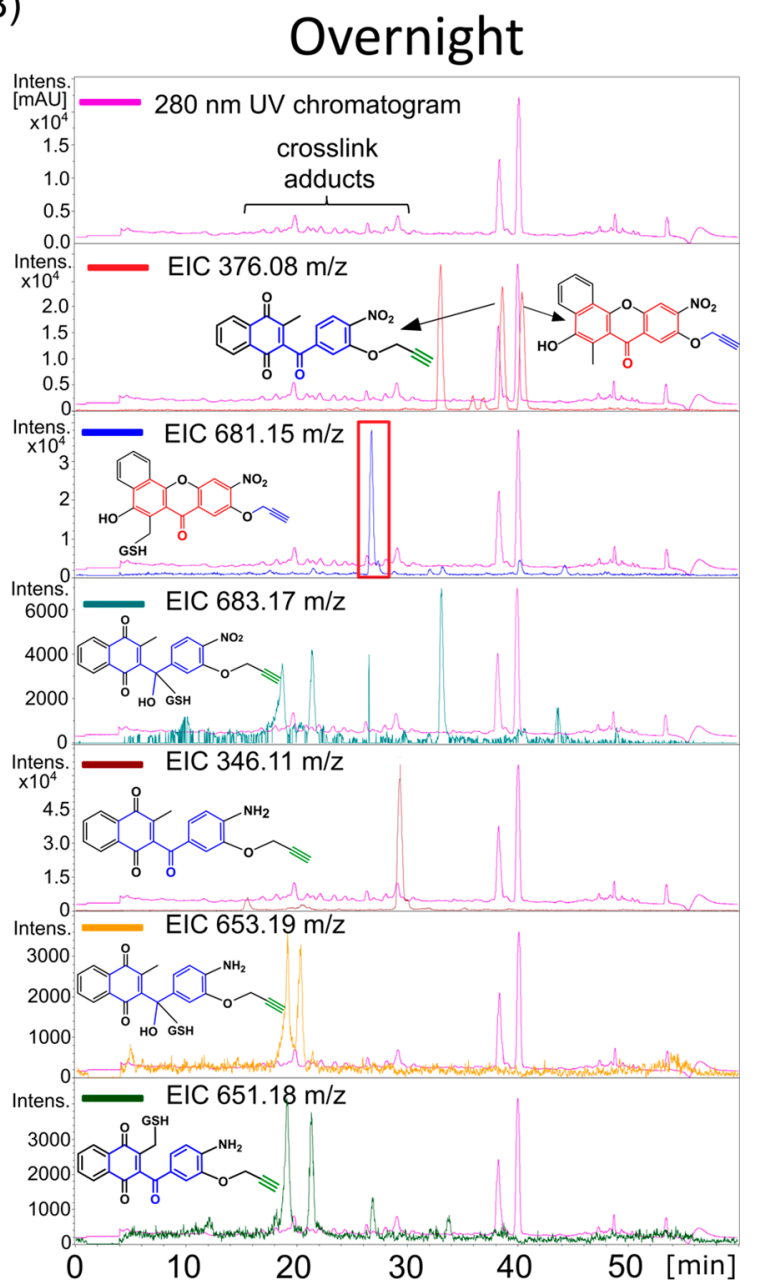

Figure 6. Photoreduction of probe 9 generates multiple probe-insertion products with GSH. (A) $280 \mathrm{~nm}$ UV-chromatogram overlaid with extracted ion chromatograms (EIC) corresponding to detected adduct and probe species. Reaction analyzed after 10 min of UV-irradiation with GSH and probe $9(\mathrm{RT}=39 \mathrm{~min})$. Red box indicates position of 2-(S-methyl) adduct peak $(\mathrm{RT}=23 \mathrm{~min})$. (B) $280 \mathrm{~nm}$ UV-chromatogram and EICs for an overnight photoreaction of probe 9 with GSH. Red box indicates position of 9-BX adduct (RT = 26.5 min). (C) MS/MS spectra of probe 9 peak $(\mathrm{RT}=39 \mathrm{~min}$; left panel) and 9-BX peak $(\mathrm{RT}=40.5 \mathrm{~min}$; right panel) from the reaction depicted in $\mathrm{B})$.

formation. Several studies have clearly exemplified the photoreduction of quinones and subsequent intramolecular cyclization of a phenoxy radical, ${ }^{40-44}$ which effectively occurred in the presence of a H-donor. It is important to note that in these experiments, GSH can act as both reductant and H-donor.

Phenolate radical in position C-4 of the diradicaloid reduced intermediate promotes the intramolecular oxidative phenolic coupling. The methyl group in ortho to the free phenolate radical of the resulting benzoxanthone possesses a very labile $-\mathrm{H}$, which releases a benzoxanthone-derived enone owing to the favored energetically structure. The electrophilic enone undergoes Michael addition with GSH leading to the benzoxanthone adduct (theoretical $m / z=681.16$ ) in perfect agreement with the observed mass peak at $m / z=681.16$. It is worth highlighting that the initial photoirradiation of probe 6 
Scheme 3. Mechanism of Formation of Both Observed Insertion Products (Blue Box) via Pathway 3 upon Photoirradiation of the ABPP Probe 9 with Glutathione ${ }^{a}$
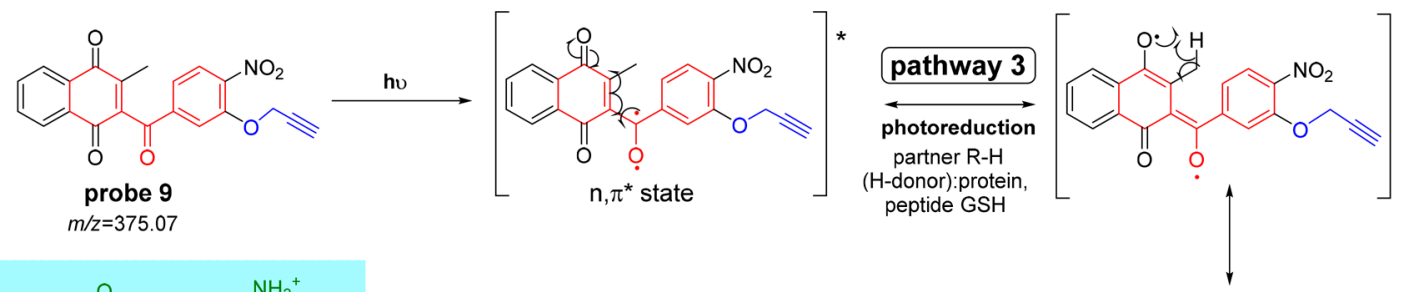

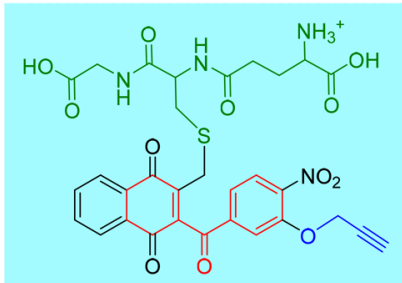

2-(SG-methyl)-probe 9 adduct calculated $\mathrm{m} / \mathrm{z}$ adduct $=681.15[\mathrm{M}+\mathrm{H}]^{+}$ observed $\mathrm{m} / \mathrm{z}$ adduct $=681.16$

Products of photoirradiation

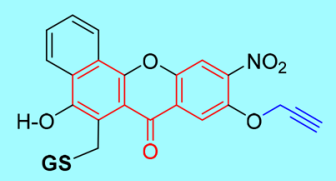

benzoxanthone 9-BX adduct $\mathrm{m} / \mathrm{z}$ [probe fragment] $=374.07$ calculated $\mathrm{m} / \mathrm{z}$ adduct $=681.14[\mathrm{M}+\mathrm{H}]^{+}$ observed $\mathrm{m} / \mathbf{z}$ adduct $=681.16$

(same product as in pathway 2)

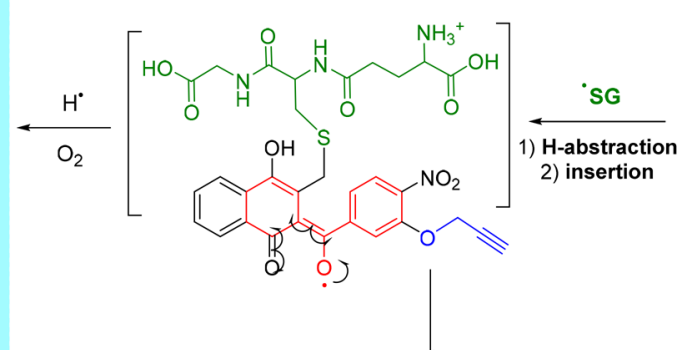<smiles>CC#CCOc1cc(/C(O)=C2\C(=O)c3ccccc3C(O)=C2C)ccc1[N+](=O)[O-]</smiles><smiles>CC#CCOc1cc(C(=O)c2c(CS)c(O)c3ccccc3c2O)ccc1[N+](=O)[O-]</smiles>
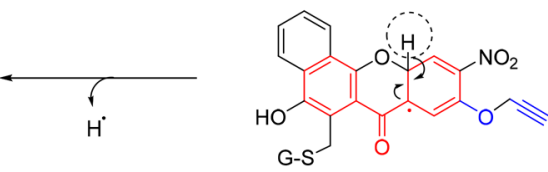

1) $\mathrm{H}$-abstraction

2) intramolecular oxidative phenolic coupling

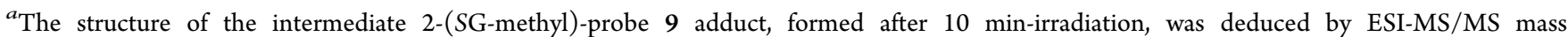
spectrometry.

with nMet did show an additional mass peak $(m / z=524.1)$, albeit with lower intensity, in the FD-MS spectrum (Figure $2 \mathrm{~A}$ ), attesting to the expression of two pathways occurring in the photochemical reaction.

Indeed, additional MS/MS analysis of the GSH adduct revealed that the generated probe fragment is benzoxanthone and that it was bound to the peptides at the sulfur atom of the cysteine residue (Figures 6C, S18). Consequently, a major formed probe species with the retention time of $40.2 \mathrm{~min}$ and $m / z=376.08$ (identical to the probe 9 mass) found after photoirradiation was identified as the benzoxanthone (Figure $6 \mathrm{~B}, \mathrm{C})$. This compound was not detected in the nonirradiated control (Figure S19A) or after $10 \mathrm{~min}$ of irradiation (Figure $6 \mathrm{~A})$, suggesting that prolonged photoreduction time is necessary to generate the cyclization product. Additionally, the newly found species underwent deprotonation overtime forming the predicted and reactive enone of pathway $2(\mathrm{~m} / z=$ 374.07) (Figures S20, S21E). Incubation of synthesized PDOBX with GSH confirmed the BX reactivity toward free thiol of GSH (Figures S22A, S22B, S23).

Interestingly, although no benzoxanthone is formed after 10 min of UV-irradiation of PD metabolite $\mathbf{P D O}_{\mathrm{ox}}$, or probe 9, with GSH, the reactions also gave rise to adducts missing two hydrogen atoms (Figures 6A, S22C). MS/MS analysis identified this compound as a 2-(S-glutathionyl-substitutedmethyl)-3-(benzoyl)-1,4-naphthoquinone (shortened as 2(GS-methyl)-PDO or 2-(GS-methyl)-probe 9) (Figures
S24A, S25). Surprisingly, the 2-(SG-methyl)-9 is not present upon overnight irradiation of probe 9 and GSH, suggesting that the species is an intermediate formed in the synthesis of 9BX-SG, according to pathway 3 (Scheme 3).

To further support our findings on the occurrence of pathways 2 and 3 occurrence, we substituted GSH in the reaction with another nucleophilic agent with a thiol groupthiophenol. LC-MS showed that already after $10 \mathrm{~min}$ of irradiation of PDO or probe 9, benzoxanthones as well as adducts lacking two hydrogens were formed (Figures S26, S27).

However, the suggested pathways are not mutually exclusive as a more careful LC-MS/MS analysis of the probe 9 reaction mixtures with GSH or thiophenol revealed that formation of benzophenone-like adducts occurred as well (Figures 6B, S24B, S26B, S28). Furthermore, in photoreactions, the nitro group from probe 9 was photoreduced to an amine, ${ }^{35}$ which has given rise to amine-substituted benzophenone adducts and -(SG-methyl)-9 adducts (Figures 6B, S29, S30).

With that, we demonstrated that probe 9 is able to efficiently cross-link to a peptide and that the corresponding peptideABPP adducts can be detected by MS analysis.

Importantly, three labeling pathways were evidenced to occur in the photoirradiation experiments involving the metabolite $\mathbf{P D O} \mathbf{o x}_{\text {or }}$ or probe $\mathbf{9}$ and $\mathrm{GSH}$, as depicted in Schemes 2 and 3. Using the LC-MS/MS approach, we were able to detect the main intermediates and products of the 
A)
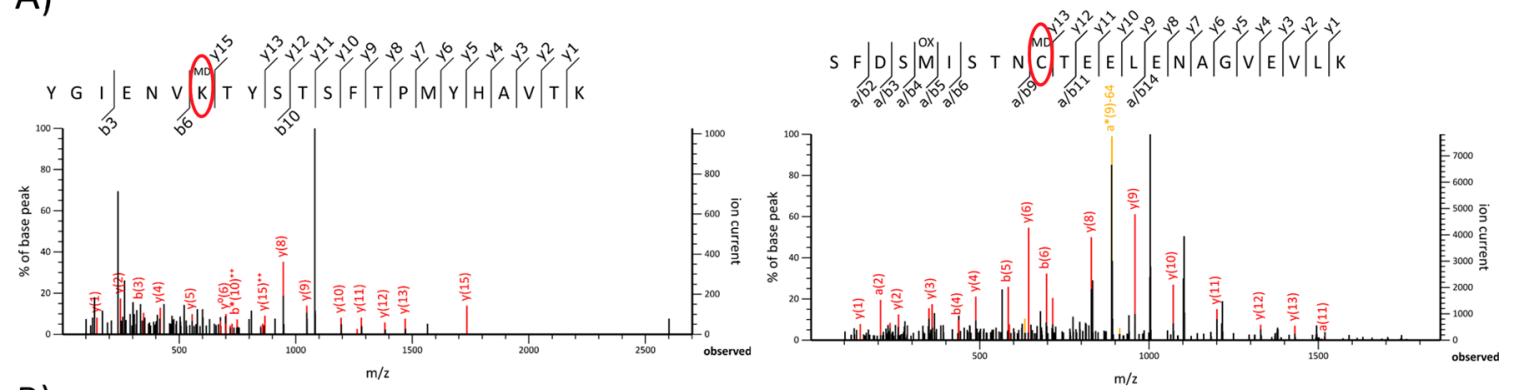

B)

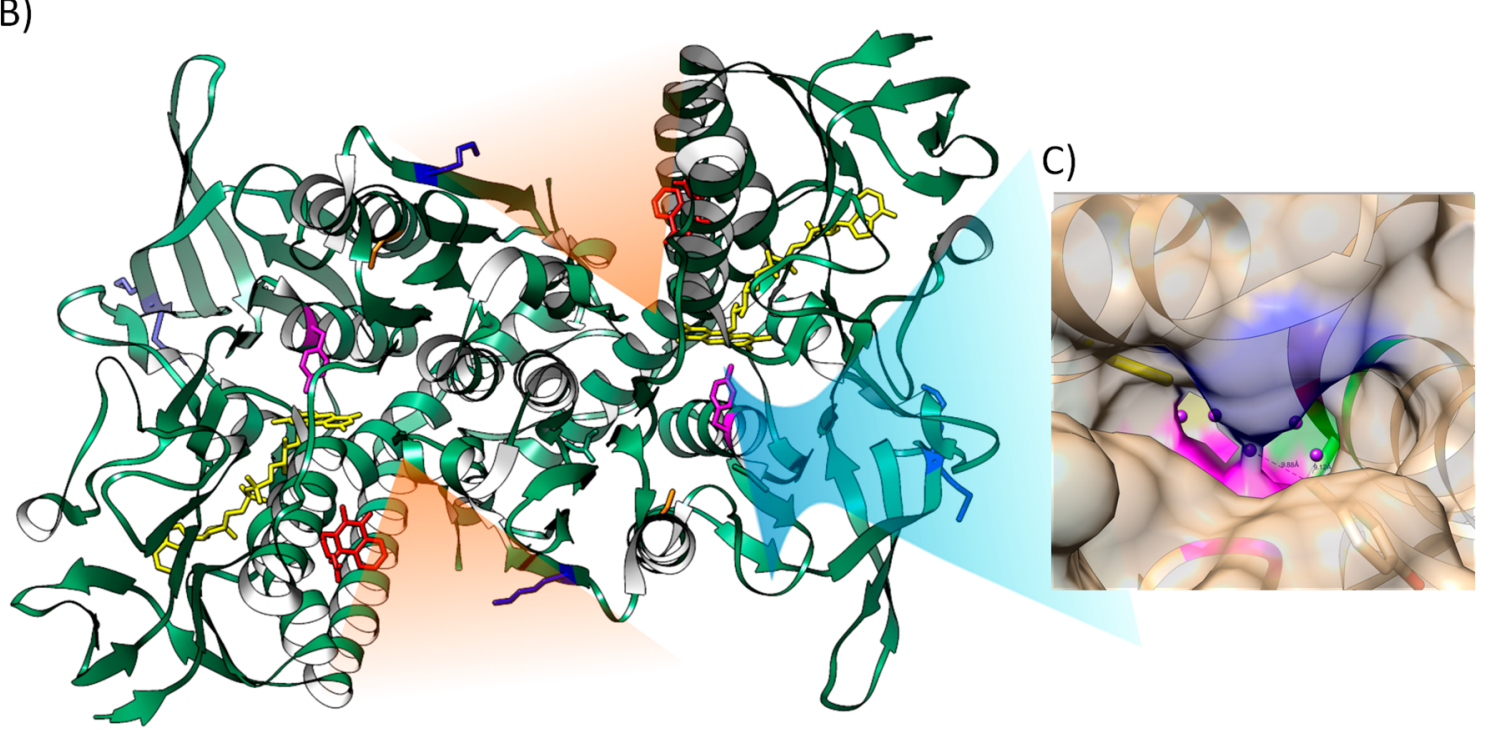

Figure 7. Probe 9 cross-links to $h$ GR (A) MS/MS fragmentation pattern of identified peptides of $h$ GR photoreaction mixture with probe 9. Left panel - peptide cross-linked at K397 (2893.23 Da = Y393-K416 + 9 - $18 \mathrm{Da}$; dehydration is common for benzophenone adducts). Right panel peptide cross-linked at C234 (2874.23 + 9-BX[ $\left.\left[\mathrm{NH}_{2}\right] \mathrm{Da}\right)$. Red circles indicate identified cross-linking sight. (B) Left panel - position of K256-7, K397 (blue), C234 (orange), Tyr197 (pink), and FAD (yellow) have been marked on the previously reported $h$ GR dimer structure cross-linked to menadione analogue (red). The substrate binding cleft leading to the catalytic disulfide bridge is visible between K397 and menadione core (orange triangle). (C) Magnification on C234 (yellow) containing the binding pocket with indicated water molecules (violet balls). Surface of A241 (blue) and H374 (pink) at pocked opening and V200 (green) in cavity is visible.

pathways: the probe, the benzophenone-like adduct, the 2(SG-methyl)-probe adduct, the cyclized probe-BX, the probe$\mathbf{B X}$-derived enone, and the probe-BX insertion adduct.

\section{Probe Cycling with Glutathione Reductase Generates Benzoxanthone}

As for photoreduction, the benzoxanthone formation has been postulated to occur during several cycles of enzymatic (GR) le-reduction of PDOox (Figure 1A). However, the metabolite was only indirectly detected by electrochemical measurements of PDO derivatives due to its minor amount. ${ }^{31}$ To prove definitively that PDO-BX is generated by continuous redoxcycling of the drug under $h \mathrm{GR}$ catalysis, we analyzed such reaction by LC-MS/MS after $6 \mathrm{~h}$ of regular addition of $\mathrm{NADPH}$. The BX-derived enone could be found in reactions in open air (Figures S21B, S21C) but not in the deoxidized control where redox-cycling was not possible due to the absence of oxidants like oxygen (Figure S21A). This clearly demonstrates that PDO-BX is indeed a product of PD metabolite redox-cycling (Figure 1A).

In addition, we investigated similarities in the $\mathbf{B X}$ formation during the redox-cycling processes during photoreduction and GR catalysis. For this, we irradiated $h \mathrm{GR}$ with probe 9 in oxygen-free conditions. Interestingly, despite the lack of oxygen, we were able to obtain $\mathbf{9 - B X}$ from probe $\mathbf{9}$ after 10 min of UV-irradiation with $h \mathrm{GR}$ (Figure S21D), although this was not possible in a comparable period of time when GSH was acting as a nucleophile. This demonstrates that the presence of the enzyme is enough to accelerate light-induced formation of 9-BX. Indeed, the UV-photoreduction process can mimic the reduction of naphthoquinone by NADPHreduced enzyme in this pathway, indicating that both processes might share similarities. Generation of $\mathbf{B X}$ from $\mathbf{P D O}_{\mathrm{ox}}$ or probe 9 was also possible in the presence of thiophenol after $10 \mathrm{~min}$ of photoirradiation. However, the cysteine thiol group in GSH only led to minor formation of PDO-BX even after overnight UV-irradiation (Figure S22 compared to S26). The results obtained with $h \mathrm{GR}$ upon irradiation imply that the protein cysteines might be more reactive than GSH. Alternatively, the entropic interaction between the naphthoquinone and the enzyme might play a mutual influence on each other upon transferring electrons and kinetically favor pathways 2-3 following probe binding to a cavity where the molecular environment favors BX formation.

\section{Using Glutathione Reductase as a Model for Photoreaction}

To test the ability of the probes to interact with protein targets and to understand the exact probe binding/reduction site in GR structure we studied the cross-linking pattern of an ABPP 
A)

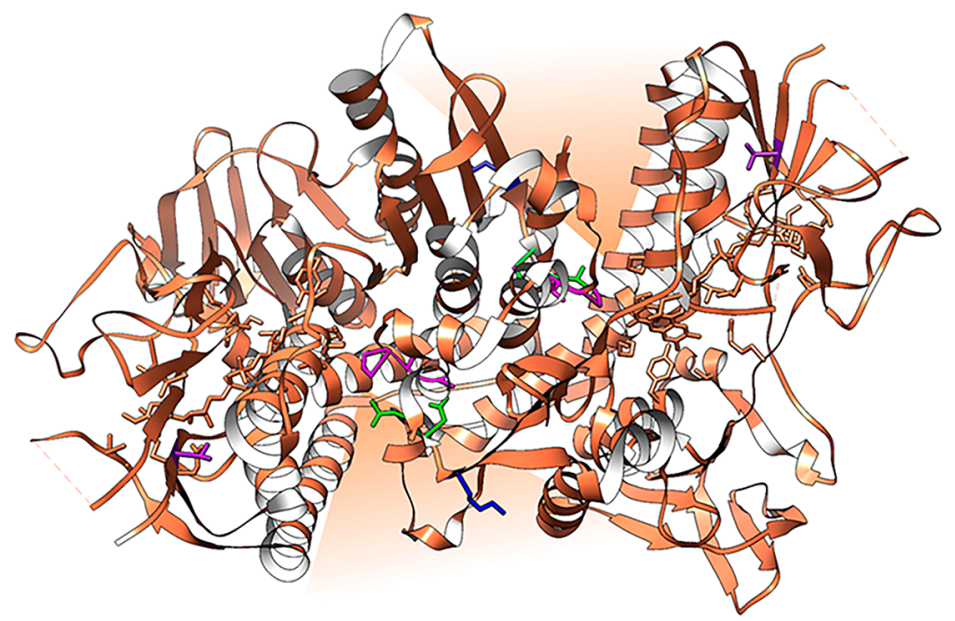

B)

hGR
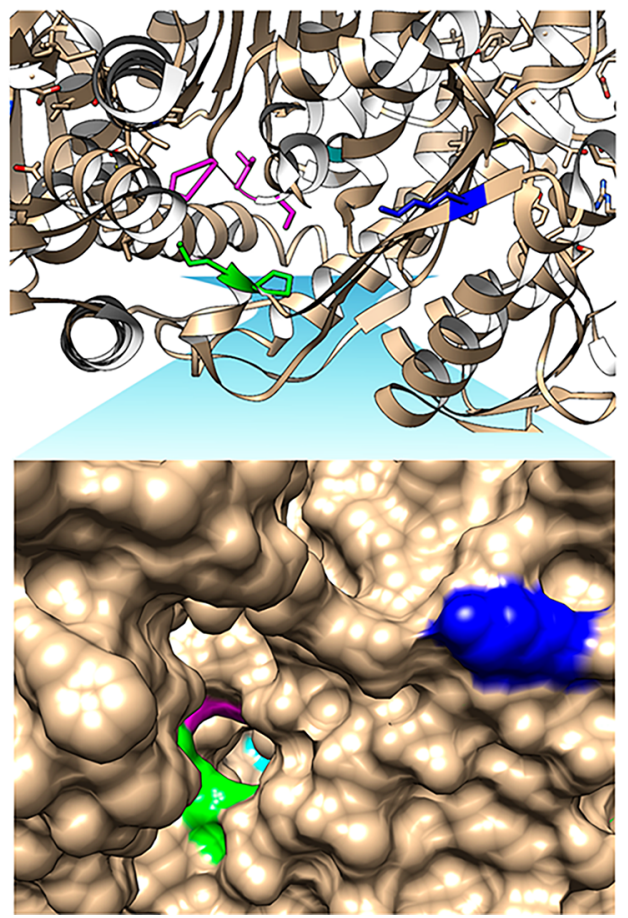

PfGR
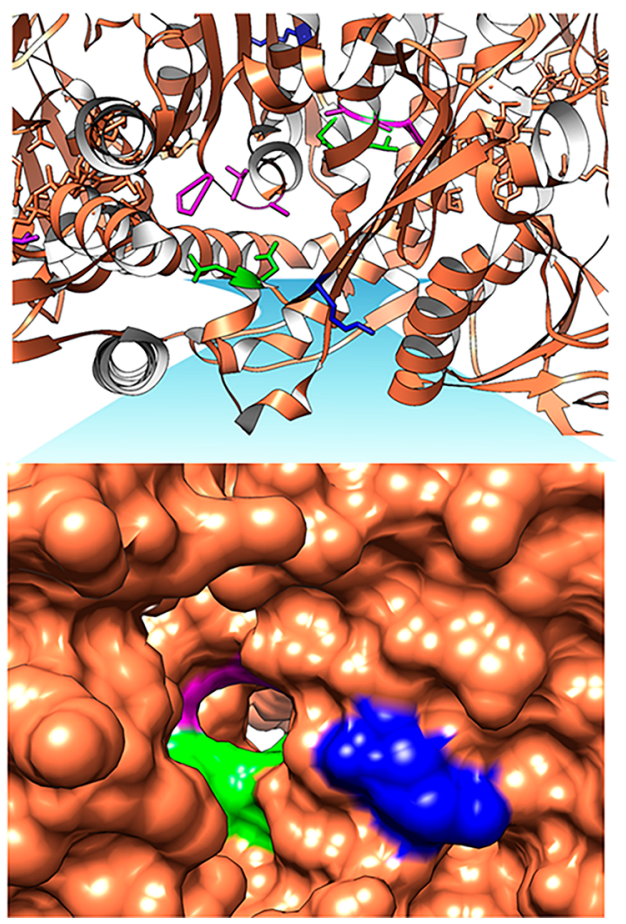

Figure 8. Probe 9 cross-links to PfGR. (A) Positions of cross-linked amino acids (K415 - blue, V6 - pink) to probe 9 in the Pf GR structure. The substrate binding cleft leading to the catalytic disulfide bridge and interspace cavity opening is indicated by the orange triangles. (B) Images picturing the distance between cross-linked K397 in hGR (left panels), K415 in PfGR (right panels), and the interspace cavity opening. Upper panel - amino acid positions on protein chain. Lower panels - surface density of cavity opening. Blue - cross-linked lysine; Green and violet amino acids of the cavity opening.

probe with GR upon photoirradiation. Enzymatic inhibition assays proved that the ABPP probes series (e.g., probes 9 and 6) with a EWG (i.e., $\mathrm{NO}_{2}$ ) in para-position to the benzoyl moiety possess the highest inhibitory potency toward $h \mathrm{GR}$ among all probes. Furthermore, considering the better solubility and photoreactivity of probe 9 , we selected it as the best ABPP probe for studies with model proteins $h \mathrm{GR}$ and PfGR.

Mass spectrometry analysis confirmed probe 9- $h \mathrm{GR}$ or -PfGR adduct formation. Similarly to GSH cross-linking, the adduct $\mathrm{m} / \mathrm{z}$ suggested the formation of GR-probe products such as benzophenone-type adduct $(+376 \mathrm{Da})$ and $\mathbf{9 - B X}$ or 2(S-methyl)-9 (+374 Da) adducts as well as species with reduced nitro group (346.11 and $344.10 \mathrm{Da}$ )(Figure S31).
Importantly no significant cross-linked peptides (Mascot score >30) have been identified during MS analysis of UV-irradiated negative control BSA incubated with 9 and the UV-irradiated GRs alone.

Interestingly, the cross-linking sites associated to 9-BX or 2( $S$-methyl)-9 were found in sites distinct from the active cysteines. Alkylation of GR was pinpointed at Lys residues whose intrinsically nucleophilic $\varepsilon$-amines confer important roles. Beyond cysteines, lysines represent a source for covalent probe development, and several studies on epigenetics in vivo have started to identify and map the Lys ligand ability of the human proteome. ${ }^{45}$ We can assume that the highly electrophilic BX-derived enone might be attacked by the intrinsically nucleophilic lysine $\varepsilon$-amine (Scheme 3 ). Furthermore, Lys 
cross-linking would explain why this amino acid is miscleaved after trypsin digestion in a large portion of identified peptide adducts (Figure S31). Similar cleavage blocking has been reported in MS studies when Lys is targeted by electrophiles and supports our correct identification of the adducts. ${ }^{45}$

Analysis by MS/MS of the probe 9-cross-linked peptide adducts identified three $h \mathrm{GR}$ peptides with high confidence (Figures 7A, S31A). The identification of these adducts several times confirms that the probe 9 can be used as a photoreactive $\mathrm{ABPP}$ probe to bind to target proteins. The involved binding site between K255 and T257 on peptide E253-R272 is located on the exposed surface of the protein, away from the protein catalytic centers, in this apparently nonfunctional region. However, the two other identified binding sites lie in known functionally related regions.

The cross-linking position (K397) of peptide Y393-K416 does not reside in known binding pockets of $h \mathrm{GR}$ (Figure $7 \mathrm{~A}, \mathrm{~B})$. Interestingly, the binding locus correlates to previous enzyme kinetic analyses performed with 3-benzoylmenadiones exhibiting uncompetitive GR inhibition. ${ }^{17}$ Indeed, it is localized in the interface domain, known to mediate the dimerization of the protein. The domain is crucial for GR activity as the enzyme is not active as a monomer. Additionally, in the interface domain, at the 2-fold symmetry axis of the homodimeric protein, a cavity is present, which was reported to bind numerous GR inhibitors, such as 2-methyl-1,4-NQ (menadione), ${ }^{34}$ 6-hydroxy-3-oxo-3H-xanthene-9-propionic acid, $^{46}$ a series of 10 -arylisoalloxazines, ${ }^{47}$ and $S-(2,4-$ dinitrophenyl) glutathione. ${ }^{48}$ The cavity does not have a direct connection with the $\mathrm{NADPH}$ or FAD binding sites. It is linked to the external surface of the protein and to the GSSG binding site by two pairs of short channels. The channel pair openings, which are located in the catalytic center, emerge at the bottom of the $\mathrm{V}$-shaped catalytic crevices in close proximity to the redox-active disulfide bridges. Significantly, in total, 41 amino acids of both subunits participate to line the GSSG binding site in $h \mathrm{GR}^{33}$ It was suggested that compounds docked in the cavity ${ }^{49}$ could either trigger structural changes disturbing the dimer stability leading to decrease of enzyme activity or interfere with the redox potential of the flavin.

Interestingly, the amino acids of the channel opening (403FTPMYH-408) are present in the identified peptide where K399 was alkylated by probe 9 , however, separated by a distance of 19-25 $\AA$ from the identified cross-link site and 9.5-19 $\AA$ from the active Cys in the GSSG binding site. It is possible that the original interaction site does not overlay with the alkylation site especially considering the reactivity of Lys toward BX. In line, when probe 9 was cross-linked with PfGR, instead of $h \mathrm{GR}$, the peptide that was identified with the highest confidence (I411-K431)(Figure S31B) is the exact homologous region of peptide Y393-K416 in hGR (Figure S31A). Moreover, compared with $h \mathrm{GR}$, the suggested part cross-linked to the probe in this peptide (411-IYESKFT-417) contains a K415 to S402 substitution, which lies in proximity to the channel opening (Figure 8A,B). K415 was miscleaved during trypsin digestion indicating the exact probe modification site at this amino acid. Strikingly, the peptide sequence prior to the cavity is conserved between $P f \mathrm{GR}$ and $h \mathrm{GR}$ with a high degree of identity emphasizing the importance of this region ${ }^{49}$ (Figure 8).

The amine generated upon nitro group reduction in the 9$\mathbf{B X}\left[\mathrm{NH}_{2}\right]$-peptide $\mathrm{S} 225-\mathrm{K} 247$ adduct was localized on the free cysteine Cys234 lying in proximity to enzyme's catalytic center where $\mathrm{FAD}$ is reduced by $\mathrm{NADPH}$, especially very close to the ultraconserved tyrosine 197 . Tyr197 serves as gate keeper of cofactor access to FAD because of its ability to flip and block NAPDH positioning near FAD. ${ }^{50}$

Structural analysis shows that Cys234 is part of a sizable pocket that extends into it all the way from the surface near the side chain of Ala 241 (Figure 7C). The pocket lies in a relatively accessible region, which directly interacts with a network of water molecules. Since the pocket is partly lined with nonpolar side chains, this could allow the naphthoquinone to displace the water molecules and gain access to Cys234. Trapping of the probe could additionally be bolstered by intrinsic reactivity of the $\mathbf{9 - B X}$ toward cysteine. In fact, Cys234 might have promoted the formation of 9-BX via pathways 2 or 3 (Schemes 2 and 3). When testing the orthologous Plasmodium enzyme PfGR, cross-linking with probe 9 did not occur at the homologous peptide, probably because of the lack of cysteine in this region in comparison to the equivalent in $h \mathrm{GR}$. Of note, the pocket does not appear to have direct access to Tyr197 as it is additionally blocked by Val200 or Cys234 itself. Nevertheless, Cys234 and especially the surrounding cavity represent an interesting target for future PD MoA investigation. A clearer picture of its importance should be studied in the future by generating $h \mathrm{GR}$ mutants for enzyme kinetics and drug binding/reduction evaluation.

Photolabeling of $h$ GR and Pull-Down of Labeled Protein Adducts

Having established the cross-linking and click conditions for the probes as well as selection of the most efficient ones for ABPP, we tested their labeling capability of proteins on $h \mathrm{GR}$. Cross-linking with 9 and subsequent click reaction allowed for efficient RA attachment on hGR (Figure S32). Similarly, tagging with BA after cross-linking with 7 or 9 followed by pull-down with avidine of labeled adducts proves the ability of the probes to target and isolate proteins (Figure 9). Both

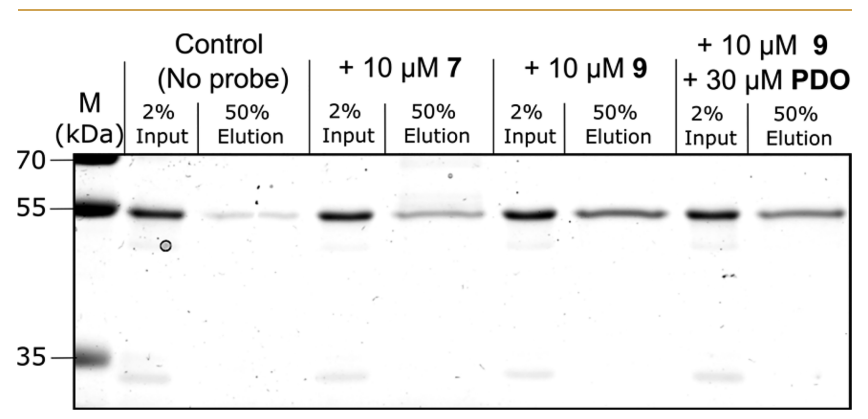

Figure 9. Pull-down of $h$ GR labeled with ABPP probes 7 and 9 and clicked with biotin tag. SDS-PAGE gel stained with Coomassie is pictured. For each reaction, $2 \%$ of the reaction before pulldown and $50 \%$ of the elution after avidin binding were loaded on the gel. $h \mathrm{GR}$ is localized at the height of the $55 \mathrm{kDa}$ marker band. $\mathrm{M}-$ marker.

tagging reactions of probe 9 with RA and BA are competitive toward nonclickable drug analogues (6 in RA and PDO in BA labeling), demonstrating the specificity of the labeling. Altogether, we evidenced that both the cross-linking and click reaction of our probes can be combined for the ABPP strategy.

The plasmodione-derived benzoxanthone is a strong electrophile with relevant meaning for the antiplasmodial plasmodione. The PDO-BX 4 has already been proposed to be a key PD metabolite (Figure 1A). ${ }^{20,21}$ Previously, we evidenced the 
A)

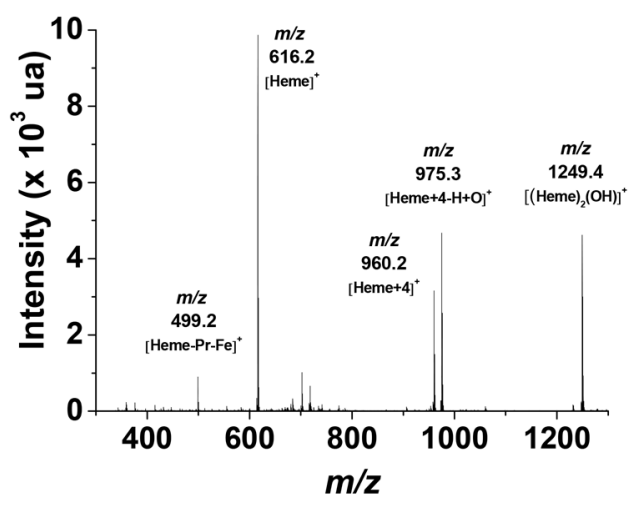

B)

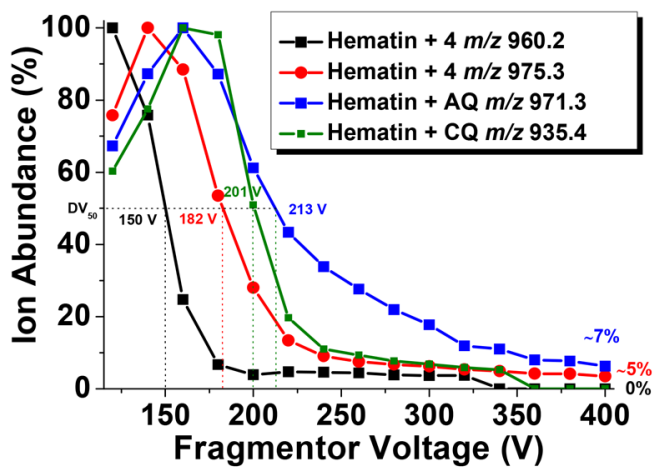

C)

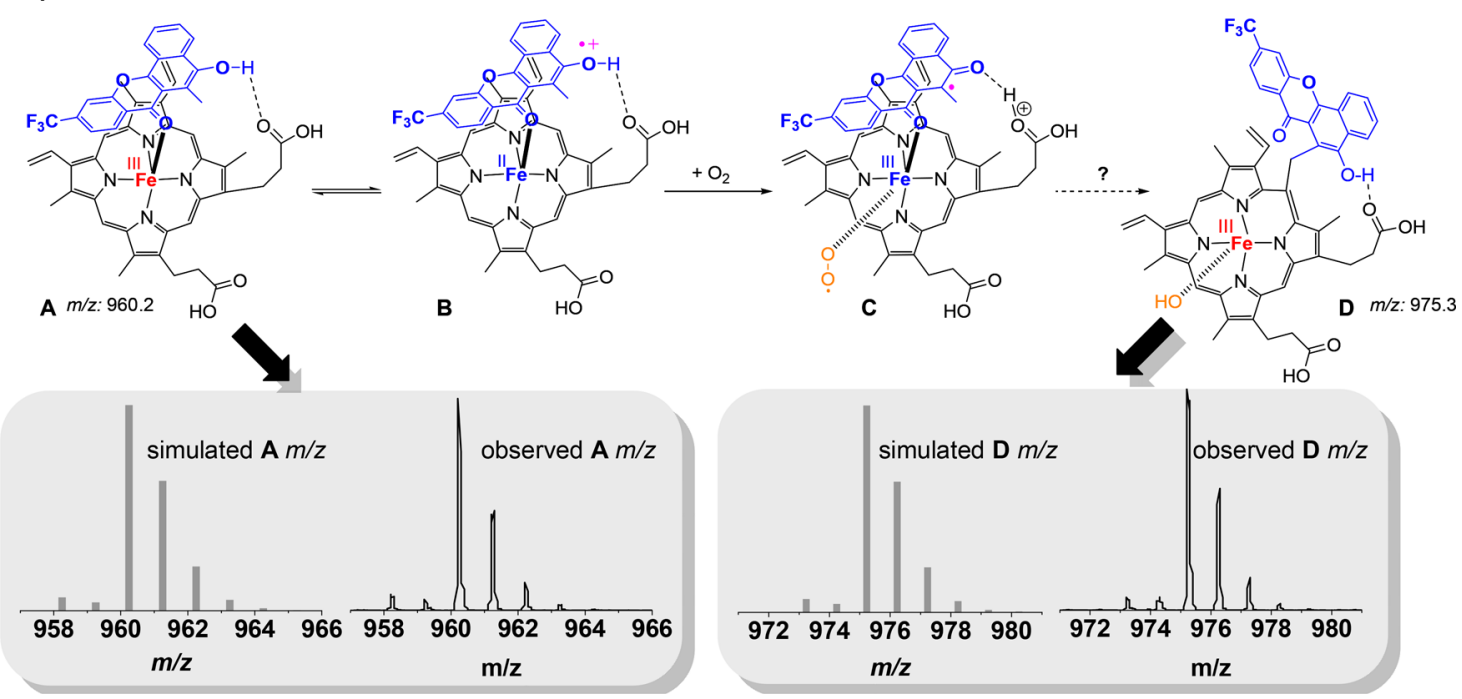

Figure 10. ESI-MS and CID-MS analysis of PDO-BX 4-heme complexes. (A) ESI mass spectrum (exit potential: $120 \mathrm{~V}$ ) of a 1:1 mixture of $50 \mu \mathrm{M}$ heme and $50 \mu \mathrm{M}$ PDO-BX 4 in $\mathrm{H}_{2} \mathrm{O} / \mathrm{CH}_{3} \mathrm{CN}(5 / 95)-1 \%$ formic acid. (B) Stability responses of the BX 4-heme (at $\mathrm{m} / z=960.2$ and at 975.3), AQ-heme (at $m / z=971.3$ ) and CQ-heme (at $m / z=935.4$ ) complexes obtained by CID-MS experiments. ESI-MS $; 120 \mathrm{~V}<$ fragmentor $<400 \mathrm{~V}$ with 20 V increments. (C) Proposed molecular structure of iron ${ }^{\text {III }}$-hematin species alkylated by the BX 4 and comparison between simulated and observed mass signatures of species $\mathrm{A}$ and $\mathrm{D}$.

formation of a PDO-hematin complex by binding titrations. ${ }^{20}$ Having demonstrated the electrophilic nature of the BX 4derived enone, we used a collision-induced dissociation tandem mass spectrometry (CID- MS) methodology to characterize the complex in detail. ${ }^{51}$ In particular, two intense PDO-BX-heme adducts at $m / z=960.2\left([\text { heme+PDO }]^{+}\right)$and $m / z=975.3$ (formally $[\mathrm{Heme}+\mathbf{B X} \mathbf{4}-\mathrm{H}+\mathrm{O}]^{+}$) were clearly detected (Figure 10A). The first BX 4-heme adduct at $m / z=$ 960.2 corresponds to a $\pi-\pi$ complex. This feature is assessed by the weak dissociation voltage $\mathrm{DV}_{50}(150 \mathrm{~V})$ and the absence of a residual complex at high fragmentor voltage (Figure 10B). In addition, the $\pi$-stacking in the PDO-hematin complex might be strengthened by additional interactions such as hydrogen bonding between the propionate of the heme side chain $^{52}$ and the phenol in PDO-BX and $\mathrm{Fe}^{\mathrm{III}}$ axial coordination of the BX carbonyl unit (Figure 10C, species A). It is noteworthy that PDO-BX can be oxidized $\left(E_{\mathrm{pa}}=-50 \mathrm{mV}\right.$ and $-208 \mathrm{mV}$ ) through its phenolic moiety and might undergo an exchange of electron(s) with the tightly bound $\mathrm{Fe}^{\mathrm{III}}$ heme. The intramolecular PDO $\rightarrow \mathrm{Fe}^{\mathrm{III}}$ heme 1e- transfer is favored by hydrogen bonding ${ }^{52}$ and generates a carbon radical at the $\mathrm{BX}$ core (Figure 10C, species B).

The concomitantly formed $\mathrm{Fe}^{\mathrm{II}}$ heme from species $\mathrm{B}$ binds $\mathrm{O}_{2}$, and the resulting species $\mathrm{C}$ (Figure 10C) might be attacked by the nucleophilic $\alpha$-keto carbon radical ${ }^{53}$ of the tightly bound $\mathbf{B X}$, ultimately leading to hematin meso-alkylation ${ }^{54}$ by PDO-BX, as suggested from the CID-ESI-MS experiments (second adduct at $m / z$ 975.3). It is noteworthy that the $\mathrm{DV}_{50}$ value of this second PDO-heme adduct is markedly increased $(+32 \mathrm{~V})$, and a significant amount of the complex is observed at high fragmentor voltage, which is therefore indicative of a very stable heme adduct ( $\sim 5 \%$ for PDO-heme adduct and $\sim 7 \%$ for the antimalarial drug amodiaquine (AQ)-heme adduct used as reported reference). In this experiment (Figure 10B), the antimalarial chloroquine (CQ), known to be a reversible heme binder did not show a residual covalent adduct at high fragmentor voltage. Similarly, when probe 9 was UVirradiated with GSH, the formed benzoxanthone was demonstrated to be reactive toward heme, when added to the reaction, leading to the generation of the adduct $\mathbf{9 - B X}-$ heme and its hydrated version (Figure S33). Together with the 
CID-MS experiments, this proves that the previously observed PDO-BX-heme complex is covalently linked to heme through the reactive enone alkylation. The structural signature of this alkylated hematin product is tentatively proposed in species $\mathrm{D}$ (Figure 10C), following reaction of the quinone methide radical at the meso-position of the tetrapyrrole and release of a water molecule, as already demonstrated for artemisinin. ${ }^{54}$ This suggested that the heme alkylation product has to be regarded as the result of the formation of a key carbon radical generated from a redox-active agent in redox-driven bioactivation processes and a relevant reaction to the MoA occurring in the parasite in vivo.

Such contribution needs more detailed investigations to understand the MoA of the redox-active lead animalarial PD. Interestingly, the data obtained with PDO-BX are reminiscent of the hypothesized formation of xanthones to explain the potentiation of antimalarial activities of polyhydroxylated benzophenone derivatives tested in the presence of Fenton catalysts upon catalysis of redox-active metals such as $\mathrm{Fe}^{\mathrm{III}} .55,56$ In the present study, upon oxidative phenolic coupling of $\mathbf{P D O}_{\text {red }}$ BX releases a powerful electrophile that can be attacked by the nucleophilic species present in the reaction, $\mathrm{GSH}$, the terminal $\varepsilon$-amine group of lysine-like $\mathrm{K} 397$ in $h \mathrm{GR}$, or heme.

\section{Evaluation of the Antimalarial Properties of PD-ABPP}

To validate the applicability of ABPPs in parasites, we then evaluated the antimalarial activity of the five newly synthesized 3-benz(o)ylmenadione-based ABPP probes (7-11, Table 2).

Table 2. $\mathrm{IC}_{50}$ Values for 3-Benz(o)ylmenadione Derivatives Determined from Growth Inhibition Assays with Highly Synchronized $P$. falciparum Strain Dd2

\begin{tabular}{clcc} 
& & \multicolumn{2}{c}{$\mathrm{IC}_{50}$} \\
\cline { 3 - 4 } series & compound & $\mathrm{Dd}^{a, b}(\mathrm{nM})$ & $(\mu \mathrm{M})^{c}$ \\
3-benzoylmenadiones & $\mathbf{6}$ & $513 \pm 287$ & 24.0 \\
& 7 & $1806 \pm 302$ & 20.5 \\
& $\mathbf{8}$ & $2993 \pm 750$ & 25.8 \\
& $\mathbf{9}$ & $417 \pm 222$ & 42.2 \\
3-benzylmenadiones & $\mathbf{1 0}$ & $>5000$ & 29.4 \\
& $\mathbf{1 1}$ & $49 \pm 15$ & $>64.0$ \\
& plasmodione & $20 \pm 5$ & $>32.0^{d}$
\end{tabular}

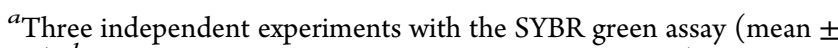
SD). ${ }^{b}$ The P. falciparum $\mathrm{Dd} 2$ strain is sensitive to DHA ( $\mathrm{IC}_{50} \mathrm{DHA}=$ $0.7 \pm 0.2$ ), to methylene blue $\left(\mathrm{IC}_{50} \mathrm{MB}=7 \pm 0.3\right)$, and resistant to chloroquine $\left(\mathrm{IC}_{50} \mathrm{CQ}=189 \pm 12\right)^{c}$ Toxicity values against human fibroblasts hMRC-5 were determined by using reported protocols. ${ }^{17}$ ${ }^{d}$ Value from ref 17 .

The potent antimalarial activities of plasmodione 1, its nitro analogue $\mathbf{5}$ and the PDO-BX $\mathbf{4}$ were already reported. ${ }^{17,20}$ As previously observed and despite being the likely key metabolites of 3-benzylmenadiones, the 3-benzoylmenadiones do not display a high antimalarial activity, with an $\mathrm{IC}_{50}$ of ca. 10-50-fold higher than the corresponding 3-benzylmenadiones. $^{17,21}$ This may be explained by the very poor internalization of 3-benzoylmenadione metabolites in pRBCs when given externally. Indeed, similar to the 3-benzoylmenadione metabolite PDO, probes 6-10 (Figure 1) are more polar and planar than the 3-benzylmenadiones ( $P D$, probes 5 and 11), likely reducing their ability to be internalized in parasites, and in accordance with the same observation in the yeast model. ${ }^{57}$ To act as the key active principle of the prodrug PD, the metabolite has thus to be generated in situ in the parasite before it can efficiently cycle with $\mathrm{NAD}(\mathrm{P}) \mathrm{H}$ dependent reductases. With respect to the ABPP properties studied in the click reaction and under photoirradiation, we observed that probes 7 and 9 are the most efficient probes to be used in photolabeling of plasmodione targets.

This result has motivated the synthesis of a first PD-ABPP, probe 11, in the 3-benzylmenadione series. Probe 11 (Figure 1) displayed an $\mathrm{IC}_{50}$ value comparable to that of $\mathbf{P D}$ regardless of substitution of the $\mathrm{CF}_{3}$ function at the para-position by an alkyne group. On the basis of our studies on the photoreactivity and clickability of 3-benz(o)ylmenadione-based $\mathrm{ABPP}$ probes, probe $\mathbf{1 1}$ is selected for future PD interactome analysis as the most efficient prodrug in killing parasites with a similar $\mathrm{IC}_{50}$ value as the value of $\mathbf{P D}$ and because it is expected to generate the most photoreactive probe 7 upon bioactivation in living Plasmodium parasites.

\section{CONCLUSIONS}

Herein, we have presented the design and the synthesis of specific (pro-)PD-ABPP probes based on the postulated MoA of the antimalarial prodrug PD. We have studied the influence of different EWGs in the 3-benzoylmenadione series on the photoreaction effectiveness of the ABPPs as well as the probes' "clickability" properties. This allowed us to select probes 7 and 9 as the most effective tools for the ABPP approach. Optimization of the ABPP methodology (e.g., click in PBS with $\mathrm{Cu}^{\mathrm{II}}$ :BCDA:TCEP $\left.(5: 1: 1)\right)$ has been successfully demonstrated by $h$ GR photolabeling with probe 7 or 9 and subsequent pull-down of labeled protein adducts. Interestingly, labeling of different nucleophilic amino acids in distinct regions of $h \mathrm{GR}$ and $P f \mathrm{GR}$ will open new directions to study GR mutants of these different residues in the context of drug development. Finally, using UV-photoirradiation, we provide evidence that (pro-)ABPP probe 11 can indeed be photooxidized in 3-benzoylmenadione-derived ABPP probe 7. While these conditions are not physiological, this result further supports the current model for PD activation and MoA. Additionally, by correlating the efficiency of (pro-)ABPP with their antimalarial activity, we concluded that the (pro-)PDABPP probe 11 should be the most effective one to be used in parasite cultures to identify the PD interactome by proteomics analysis. Identifying PD targets will be essential to further optimize the properties of this compound series and to design more active and target-specific derivatives.

Beyond the investigated plasmodione-based tools, we believe that the concept of (pro-)ABPP can be further expanded as a generalizable and emerging strategy to investigate redox-active drugs with various biological properties (e.g., anticancer, antibiotic, antiviral, antiparasitic) to identify new protein targets, while noting that other warheads than menadione are also possible.

Linking drug effects from complex reactions to killing processes/targets in parasites is one of the most challenging steps when studying the MoA of any drug. When the latter is a redox-activable prodrug it is even more difficult because a wide range of metabolites can be generated in trace amounts during redox bioactivation. One solution dealing with this quantity limit is the development ABPP probes based on already known drug metabolites, keeping in mind that the method addresses a common limitation of exogenously added probe, which does not necessarily mimic the endogenous generation of an active 
principle from a prodrug in the target living cell. Therefore, to circumvent this limitation, we designed a series of photoreactive prodrugs, which upon UV irradiation generate the same drug metabolites as those formed through redox bioactivation, and we put this concept into practice using the antimalarial agent plasmodione. Besides this applied and deep investigation about an antiplasmodial early lead agent, we believe that understanding the various parameters influencing the $\mathrm{CuAAC}$ reaction, for example, $\mathrm{Cu}(\mathrm{I})$ preincubation reaction with reductant and ligand, organic solvent, reductant and ligand ratios, $\mathrm{pH}$, buffer dilution, salts, counter-anions, is essential for the success of the CuAAC strategy. The interplay between these elusive factors is key in the setting up of the optimization of the CuAAC reaction, as demonstrated by our findings.

\section{MATERIAL AND METHODS}

\section{UV-Irradiation}

Reactions were irradiated either with a $365 \mathrm{~nm}$ light generated by a UV monochromator of $1000 \mathrm{~W}$ intensity for 8 to $10 \mathrm{~min}$ or with a $350 \mathrm{~nm}$ light generated by eight RPR-3500A lamps of $200 \mathrm{~W}$ with a Rayonet photochemical reactor overnight at a distance of $3 \mathrm{~cm}$ from the light source.

\section{Irradiation Experiments for Photobenzylic Oxidation of} the (Pro-)ABPP Benzylmenadione Probe 11 to

\section{Benzoylmenadione 7}

First, $50 \mathrm{mg}$ of 2-(4-ethynylbenzyl)-3-methylnaphthalene-1,4-dione 11 and $2 \mathrm{~mL}$ of the appropriate solvent were added in a tube. The mixture was agitated and bubbled with oxygen during $30 \mathrm{~min}$. Then, under a positive pressure of oxygen, the tube was placed in a Rayonet photochemical reactor and irradiated at $350 \mathrm{~nm}$ for $72 \mathrm{~h}$. The resulting mixture was extracted with dichloromethane if necessary, and the solvent was removed under reduced pressure. The reaction crude was directly analyzed by NMR spectroscopy.

\section{Irradiation Experiments for Model Photoreaction}

The photochemical reaction of $\mathrm{N}$-acetyl-methionine methyl ester ( $\mathrm{N}$ Ac-Met-OMe, shortened as nMet) with benzophenone and benz(o)ylmenadione 6 was carried out in a pyrex tube (filter for $h \nu<300 \mathrm{~nm}$ ) at a final concentration of $0.1 \mathrm{M}$ at a final concentration of $0.1 \mathrm{M}$ in $\mathrm{ACN}$. The reaction was irradiated at $5{ }^{\circ} \mathrm{C}$ for $24 \mathrm{~h}$ in a Rayonet reactor (at $350 \mathrm{~nm}$ ). Finally, the reaction was analyzed by fielddesorption mass spectrometry (FD-MS), as seen in Figure 2. FD-MS of the reactions was performed at Heidelberg University according to a published protocol with a JEOL JMS-700. ${ }^{58}$

\section{Standardization of UV Cross-Linking Parameters Using} nMet

The $\varepsilon^{\max }$ and $\lambda^{\max }$ of all the PD-ABPP were first analyzed by UV-vis absorption spectrophotometry in the $\lambda$ region $>300 \mathrm{~nm}$ (Figure S5). It is noteworthy to mention that the $\pi-\pi^{*}$ transitions are below 300 $\mathrm{nm}$ for all PD-ABPP probes. In addition to the intense absorption below $300 \mathrm{~nm}\left(\pi-\pi^{*}\right)$, the maximum of absorption $\lambda^{\max }\left(\pi-\pi^{*}\right.$ transitions) is about $340 \mathrm{~nm}$ for probes $7, \mathbf{8}, \mathbf{9}, \mathbf{1 1} ; 320 \mathrm{~nm}$ for probes 8 and 10; and $350 \mathrm{~nm}$ for benzophenone with low intense absorption $\left(\mathrm{n}-\pi^{*}\right.$ transitions) centered at about $400 \mathrm{~nm}$. For all probes, we selected $350 \mathrm{~nm}$ (Rayonet, $24 \mathrm{~h}$ ) or $365 \mathrm{~nm}(1000 \mathrm{~W} h \nu$ monochromator, $2 \mathrm{~min}$, at room temperature) wavelengths as the light excitation sources for studying the corresponding photoreaction because of the proximity of $\lambda^{\max }\left(\mathrm{n}-\pi^{*}\right.$ transitions $)$ of the probe and the low probability of damaging the protein.

The reaction conditions are as follows: 1 equiv of PD-ABPP +5 equiv of nMet (i.e., $100 \mu \mathrm{L}$ of $20 \mathrm{mM}$ PD-ABPP in ACN $+100 \mu \mathrm{L}$ of $1000 \mathrm{mM}$ PD-ABPP in ACN), with a total $200 \mu \mathrm{L}$ volume. The reaction mixtures were deoxygenated under strict oxygen-free conditions using argon-vacuum cycles, exposed to photoirradiation, and then analyzed by ${ }^{1} \mathrm{H}$ NMR. The covalently cross-linked products were confirmed by TLC and NMR analysis.

Inhibition Potency of ABPP Probes toward Human GR

The inhibition of $h$ GR by ABPP probes 7-10 was evaluated by using a standard GR assay ${ }^{17}$ with $100 \mu \mathrm{M}$ NADPH (Biomol) and $1 \mathrm{mM}$ GSSG (Serva) in GR buffer ( $47 \mathrm{mM}$ potassium phosphate buffer, 200 $\mathrm{mM} \mathrm{KCl}, 1 \mathrm{mM}$ EDTA, pH 6.9) at $25^{\circ} \mathrm{C}$ in a $1 \mathrm{~mL}$-cuvette using the inhibitor concentrations ranging from of 0 to $2 \mu \mathrm{M}$. The final concentration of $\mathrm{ACN}$ in the assay was $2 \%$. Initial rates of NADPH oxidation by $h \mathrm{GR}(8 \mathrm{mU}$ or $0.85 \mathrm{pmol})$ was monitored at $340 \mathrm{~nm}$ with a Cary $50 \mathrm{UV}-$ vis absorption spectrophotometer.

Photoreaction between the ABPP Probe 9 and Thiophenol, Peptides, and Proteins as Partners

For peptide cross-linking, stock solutions of GSH (Sigma) or P52C were prepared in $20 \mathrm{mM}$ PBS at $\mathrm{pH}=6.9$. Stock solutions of PDO 2 or of probe 9 were prepared in pure ACN. For thiophenol crosslinking, the stock solution of the thiol was prepared in ACN. Then, the reaction was started by mixing $3 \mathrm{mM}$ of peptide or thiophenol with $600 \mu \mathrm{M} 9$ or $100 \mu \mathrm{M} 3$ in a mixture of $1: 1 \mathrm{ACN}$ and $10 \mathrm{mM}$ PBS in $200 \mu \mathrm{L}$ volume. The reaction mixtures were deoxygenized by seven alternative cycles of vacuum and Ar flux in an anaerobic cuvette with longer argon cycles $(15 \mathrm{~s})$ than vacuum cycles $(<6 \mathrm{~s})$ to avoid ACN evaporation. The mixture was photoirradiated for $10 \mathrm{~min}$ or overnight $(\mathrm{O} / \mathrm{N})$, and the next day the solution was analyzed by HPLC-MS.

For heme alkylation by $9-\mathrm{BX}, 1.5 \mathrm{mM}$ heme solution in PBS was added to the reaction mixture containing GSH and probe 9 at completion. The resulting mixture was incubated for $2 \mathrm{~h}$ and analyzed by HPLC-MS. Hematin was generated from hemin (Sigma) by basifying the heme solution with $2 \mathrm{M} \mathrm{NaOH}$.

In the study about cross-linked adduct formation, protein photoirradiation was performed with a mixture of $6 \mu \mathrm{M} h \mathrm{GR}$ or 5 $\mu \mathrm{M}$ PfGR (or BSA - used as negative control) with $6 \mu \mathrm{M}$ or $5 \mu \mathrm{M}$ probe 9 , respectively, in $200 \mu \mathrm{L}$ of $10 \mathrm{mM}$ PBS buffer at $\mathrm{pH} 6.9$ with $2 \%$ ACN. Probe solubility in $2 \%$ ACN was assessed spectrophotometrically with a Cary 50 absorption spectrophotometer by monitoring absorbance kinetics of decreasing ABPP probe concentrations, starting with $20 \mu \mathrm{M}$ (Figure S16).

In reactions with $h \mathrm{GR}$ and the probe, $52.5 \mu \mathrm{M}$ NADPH was added to initiate the redox-cycling. The reaction mixture was deoxygenized by seven alternative vacuum and Ar flux cycles (10 s each) in an anaerobic cuvette. Subsequently, the mixture was photoirradiated for $8 \mathrm{~min}$, and afterward, $100 \mu \mathrm{L}$ of $3 \times$ Laemmli buffer was added. The next day, the samples were separated on $10 \%$ SDS-Page gels, stained with Coomassie solution, and destained according to published protocol. ${ }^{59}$ Protein bands were cut out and subjected to trypsin digestion and HPLC-MS analysis.

\section{Generation of 9-BX from ABPP Probe 9 upon $h \mathrm{GR}$ Redox-Cycling}

In order to generate $9-\mathbf{B X}, 40 \mu \mathrm{M}$ of probe 9 was allowed to redoxcycle with $h \mathrm{GR}$ and $1.44 \mathrm{mM}$ NADPH. Probe 9 stock solution was prepared in DMSO and added to the reaction mixture in the presence of $2 \%$ solvent final in $47 \mathrm{mM}$ PBS buffer in $200 \mu \mathrm{L}$ of total reaction volume. In the hemoglobin reduction assay, $80 \mu \mathrm{M}$ methemoglobin was mixed additionally to the reaction. Redox-cycling was started by addition of a $6 \mu \mathrm{L}$-aliquot of $16 \mathrm{mM}$ NADPH and $4 \mu \mathrm{M} h \mathrm{GR}$. The same amount of NADPH was added at regular $2 \mathrm{~h}$-intervals for the next $6 \mathrm{~h}$. A control sample was deoxygenized by seven vacuum-argon cycles before first addition of the separately deoxygenized NADPH solution.

\section{Generation of 9-BX from ABPP Probe 9 upon hGR} Photoreduction

Probe 9 photoreduction in the presence of $h \mathrm{GR}$ was achieved by mixing $100 \mu \mathrm{M}$ of the probe in $20 \% \mathrm{ACN}$ with $4 \mu \mathrm{M} h \mathrm{GR}$ in $47 \mathrm{mM}$ PBS buffer. Samples were deoxygenized by 7 alternative vacuum-Ar cycles with longer argon cycles $(15 \mathrm{~s})$ than vacuum cycles $(<6 \mathrm{~s})$ to 
avoid ACN evaporation. The reaction was UV-irradiated for $10 \mathrm{~min}$ and the mixture was analyzed by HPLC-MS.

\section{Successive Cross-Linking and Click Reaction with hGR}

For $h$ GR labeling $150 \mu \mathrm{L}$ of $10 \mu \mathrm{M} h \mathrm{GR}$ in $12.5 \mathrm{mM}$ PBS (potassium based) and $2 \%$ DMSO was UV irradiated in the presence of $10 \mu \mathrm{M}$ probe 7 or 9 for $10 \mathrm{~min}$. The reaction was beforehand deoxygenized by seven alternative cycles of vacuum and Ar flux. In competition assays $30 \mu \mathrm{M}$ of probe 6 or PDO was added additionally. After a 10 min photoreduction, 3.3\% DMF and $20 \mu \mathrm{M}$ RA or $10 \mu \mathrm{M}$ BA was added. The reaction was deoxygenized a second time, and $0.4 \%$ of deoxygenized SDS was added with a syringe. A click reaction was initiated by adding a 1:5:1 copper BCDA:CuSO 4 :TCEP 40 min-long preincubation mixture to a final concentration ratio of 132:660:132 $\mu \mathrm{M}$, respectively, and final volume of $200 \mu \mathrm{L}$. The reaction was incubated overnight at $30^{\circ} \mathrm{C}$. Reactions containing biotin azide (BA) were subjected to pull-down, whereas rhodamine azide (RA) reactions were mixed with $100 \mu \mathrm{L}$ of $3 \times \mathrm{Laemmli}$, heated at $60{ }^{\circ} \mathrm{C}$, and separated by SDS-PAGE. Gel fluorescence was visualized by GelDoc EZ imager (BioRad) on a blue tray (excitation $=430-460$ $\mathrm{nm}$ ). The gel was stained by Coomassie staining after fluorescence analysis.

\section{Biotin Pulldown}

Biotin-protein adducts were pulled down by binding to avidin agarose beads (Pierce). Prior to use, the beads were washed five times with 1.5 $\mathrm{mL}$ of washing buffer (47 $\mathrm{mM}$ sodium based PBS, $\mathrm{pH}$ 6.9) and centrifuged at $5000 \mathrm{~g}$ for $1 \mathrm{~min}$ at RT. Unspecific sites on the avidin agarose beads were blocked by incubating the beads for $1.5 \mathrm{~h}$ at RT with $0.5 \mathrm{mM}$ BSA. Overnight click reactions were diluted with $47 \mathrm{mM}$ PBS with $0.3 \%$ SDS to $1 \mathrm{~mL}$ of volume and incubated for $1 \mathrm{~h}$ with beads at RT. The suspension was washed once with washing buffer + $0.05 \%$ Tween 20 and once with washing buffer $+1 \%$ SDS, as well as once with washing buffer in-between, before, and after. Subsequently, the beads were centrifuged at $4500 \mathrm{~g}$ for $1 \mathrm{~min}$ at RT. Bound proteins were eluted at $96^{\circ} \mathrm{C}$ for 10 min with $80 \mu \mathrm{L}$ of Laemmli buffer. Eluted proteins were separated on $10 \%$ SDS-PAGE gel and stained with Coomassie stain.

\section{Protein Preparation for In-Gel Digestion}

The gel pieces were successively washed with $50 \mu \mathrm{L}$ of $25 \mathrm{mM}$ $\mathrm{NH}_{4} \mathrm{HCO}_{3}$ and $50 \mu \mathrm{L}$ of $\mathrm{ACN}$ (three times) and dehydrated with 100 $\mu \mathrm{L}$ of ACN before reduction in the presence of $10 \mathrm{mM}$ DTT in 25 $\mathrm{mM} \mathrm{NH}_{4} \mathrm{HCO}_{3}\left(1 \mathrm{~h}\right.$ at $57^{\circ} \mathrm{C}$ ) and alkylation in the presence of 55 $\mathrm{mM}$ iodoacetamide in $25 \mathrm{mM} \mathrm{NH} \mathrm{NCO}_{3}$. For tryptic digestion, the gel pieces were resuspended in $2 \times$ volumes of trypsin $(12.5 \mathrm{ng} / \mu \mathrm{L}$; Promega V5111) freshly diluted in $25 \mathrm{mM} \mathrm{NH}_{4} \mathrm{HCO}_{3}$ and incubated overnight at $37{ }^{\circ} \mathrm{C}$. The digested peptides were then extracted from the gel in a buffer containing $34.9 \% \mathrm{H}_{2} \mathrm{O}, 65 \% \mathrm{ACN}$, and $0.1 \%$ $\mathrm{HCOOH}$, and the excess of $\mathrm{ACN}$ was removed by evaporation and peptides analyzed by nanoLC-MS/MS.

\section{NanoLC-MS/MS Analysis}

Peptide digests analysis was performed on a nanoACQUITY UltraPerformance-LC (Waters, Milford, MA, U.S.A.) coupled to a TripleTOF $5600+$ mass spectrometer (Sciex, Framingham, U.S.A.). The samples were trapped on a $20 \times 0.18 \mathrm{~mm}, 5 \mu \mathrm{m}$ Symmetry C18 precolumn (Waters Corp.), and the peptides were separated on a nanoEase M/Z Peptide BEH C18 Column, $130 \AA ̊$, $1.7 \mu \mathrm{m}, 75 \mu \mathrm{m} \times$ $150 \mathrm{~mm}$ (Waters). The solvent system consisted of $0.1 \%$ formic acid in water (solvent A) and $0.1 \%$ formic acid in ACN (solvent B). Trapping was performed during $3 \mathrm{~min}$ at $5 \mu \mathrm{L} / \mathrm{min}$ with $99 \%$ of solvent $\mathrm{A}$ and $1 \%$ of solvent $\mathrm{B}$. Elution was performed at a flow rate of $300 \mathrm{~nL} / \mathrm{min}$, using $1-40 \%$ gradient (solvent B) over $35 \mathrm{~min}$ at $60^{\circ} \mathrm{C}$ followed by $65 \%$ (solvent B) over 5 min. The mass spectrometer was operated in positive mode, with the following settings: ion spray voltage floating (ISVF) $2300 \mathrm{~V}$, curtain gas (CUR) 25 psi, interface heater temperature (IHT) $75{ }^{\circ} \mathrm{C}$, ion source gas 1 (GS1) 2 psi, declustering potential (DP) $100 \mathrm{~V}$. Information-dependent acquisition (IDA) mode was used with top 5 MS/MS scans. The MS scan had an accumulation time of $250 \mathrm{~ms}$ on $\mathrm{m} / z$ [400-1250] range and the MS/MS scans $100 \mathrm{~ms} m / z$ [150-1600] range in high sensitivity mode. Switching criteria were set to ions with charge state of 2-4 and an abundance threshold of more than 150 counts, and exclusion time was set at 12 s. IDA rolling collision energy script was used for automatically adapting the CE. Mass calibration of the analyzer was achieved using peptides from digested BSA. The complete system was fully controlled by AnalystTF 1.6 (AB Sciex).

\section{Protein Identification}

Mass data collected during nanoLC-MS/MS were searched using a local Mascot server (Matrix Science, London, U.K.) against an inhouse-generated protein database composed of protein sequences of $h \mathrm{GR}, \mathrm{Pf} \mathrm{GR}$ and BSA using an in-house database generation toolbox (https://msda.unistra.fr). Searches were performed with selected modification (on each 20 encoded proteinogenic amino acids either +375.07 Da (9 or 9-BX), +374.07 Da (9-1 Da), +373.06 Da (9-BX) +357.06 $\mathrm{Da}\left(\mathbf{9}-\mathrm{H}_{2} \mathrm{O}\right),+356.06 \mathrm{Da}(\mathbf{9}-\mathrm{BX}-\mathrm{OH}),+358.07 \mathrm{Da}(\mathbf{9}-$ $\mathrm{OH}),+345.10 \mathrm{Da}\left(9-\mathrm{NH}_{2}\right), 343.08 \mathrm{Da}\left(9-\mathrm{BX}_{-}-\mathrm{NH}_{2}\right)$ or $+327.09 \mathrm{Da}$ $\left(9-\mathrm{NH}_{2}-\mathrm{H}_{2} \mathrm{O}\right)$, trypsin was selected as the enzyme, carbamidomethylation of cysteine $(+57 \mathrm{Da})$ and oxidation of methionine $(+16 \mathrm{Da})$ were set as variable modifications, three miscleavages were tolerated and mass tolerances on precursor, and fragment ions of $20 \mathrm{ppm}$ and $0.07 \mathrm{Da}$ were used, respectively. Modified peptides were manually validated. Selected peptides binding sites were visualized, and distances were calculated on $h \mathrm{GR}$ (PDB ID: 3GRS; 2GH5) and PfGR (PDB ID: 1ONF) structure models using Chimera software. ${ }^{60}$ HPLC-MS Analysis

LC/MS analyses were performed using an Agilent 1100 series LC coupled to a MicrOTOF-Q (Bruker Daltonics, Bremen, Germany) or to a maXis II Q-TOF mass spectrometer (Bruker). The mass spectrometer was operated in positive mode with a capillary voltage of $4500 \mathrm{~V}$. Acquisitions were performed on the mass range of 200-1850 $m / z$. Calibration was performed using the singly charged ions produced by a solution of Tune mix (G1969-85000, Agilent, U.S.A.). Data analysis was performed by using Compass DataAnalysis 4.3 (Bruker Daltonics). A cross-linking reaction mixture containing GSH and PDO 2 (or probe 9) was directly analyzed onto a HPLC connected to MicrOTOF-Q. Compounds were separated on a XBridge Peptide BEH C18 column ( $300 \AA$, $3.5 \mu \mathrm{m}, 2.1 \mathrm{~mm} \times 250$ $\mathrm{mm})$ column. The gradient was generated at a flow rate of $250 \mu \mathrm{L} /$ min using $0.1 \%$ trifluoroacetic acid (TFA) in water for mobile phase A and ACN containing $0.08 \%$ TFA for mobile phase B at $60^{\circ} \mathrm{C}$. Phase $\mathrm{B}$ was increased from 5 to $85 \%$ in $45 \mathrm{~min}$.

\section{MS Fragmentation of Collected Fractions}

Adducts synthesized in photoreactions and selected for fragmentation were purified by HPLC into specific fractions. Fragmentation of compounds and standards was performed on a hybrid electrospray quadrupole time-of-flight mass spectrometer MS (Synapt G2 HDMS, Waters, Manchester, U.K.) coupled to an automated chip-based nanoelectrospray device (Triversa Nanomate, Advion Biosciences, Ithaca, U.S.A.) operating in the positive ion mode. The MS analysis was performed on the Synapt G2 HDMS instrument with external calibration using the singly charged ions produced by an ES-TOF tuning mix (G1969-85000, Agilent, U.S.A.). The nanoelectrospray device (Triversa Nanomate) was set at $1.5 \mathrm{kV}$ on capillary, and the pressure of the nebulizer gas was 0.55 psi. Selected ions were fragmented with a collision energy ranging from 5 to $40 \mathrm{eV}$ until sufficient fragmentation was achieved.

\section{Collision-Induced Dissociation-Electrospray Mass Spectrometry Measurements}

Electrospray mass spectra of heme complexes were obtained with a Bruker Daltonics MicroTOF spectrometer (Bruker Daltonik GmgH, Bremen, Germany) equipped with an orthogonal electrospray (ESI) interface. Calibration was performed using Tuning mix (Agilent Technologies). CID experiments ${ }^{51}$ were performed with a capillary exit (cone voltage) ranging from 120 to $400 \mathrm{~V}$ with $20 \mathrm{~V}$ increments. ${ }^{61}$ Stock solution of hematin ([Fe $\left.{ }^{\text {III PPIX }}\left(\mathrm{OH}_{2}\right)\right]^{3+}$ or $\left.\left[\mathrm{Fe}^{\mathrm{III}} \text { PPIX }(\mathrm{OH})\right]^{2+}\right)$ was freshly prepared from hemin (ferriproto- 
porphyrin chloride, $\left[\mathrm{Fe}^{\mathrm{III}} \text { PPIX }(\mathrm{Cl})\right]^{2+}$ ) just before use in $50 \%$ ammonia. Stock solution of benzoxanthone BX 4 (5 mM) was prepared in ACN, while chloroquine (CQ $2.91 \mathrm{mM}$ ) and amodiaquine $(\mathrm{AQ} 2.28 \mathrm{mM})$ were prepared in water. Hematin and the substrate (4 or $\mathbf{C Q}$ or $\mathbf{A Q}$ ) were mixed together in $\mathrm{CH}_{3} \mathrm{CN} / \mathrm{H}_{2} \mathrm{O}$ $(50: 50 \mathrm{v}: \mathrm{v})$ in order to obtain equimolar concentrations of $100 \mu \mathrm{M}$. Prior to analyses, the samples were further diluted at $50 \mu \mathrm{M}$ in ACN/ $\mathrm{H}_{2} \mathrm{O} / \mathrm{HCOOH}$ (50:50:1 v:v:v). The sample solutions were then introduced into the spectrometer source with a syringe pump (Harvard type 55 1111: Harvard Apparatus Inc., South Natick, MA, U.S.A.) with a flow rate of $5 \mu \mathrm{L} \cdot \mathrm{min}^{-1}$. Stability responses of the heme-drug adducts obtained by ESI-CID experiments were drawn.

\section{Antimalarial Activity}

Antimalarial activity is represented by $\mathrm{IC}_{50}$ the concentration of biomolecule at which half of the parasites are killed. The antimalarial activity of PD-ABPP was evaluated on asexual parasite stages of the chloroquine-resistant Dd2 strain of P. falciparum. Highly synchronised young rings $(0-3 \mathrm{~h} \text { old })^{62,63}$ were treated for $72 \mathrm{~h}$ with various concentrations of PD-ABPP. For this, mature schizonts of highly synchronous parasite cultures were separated using $60 \%$ percoll gradient and the mature segmented schizonts were incubated for 3 hours for reinvasion. Remaining mature stages were then killed with $5 \%$ sorbitol and parasitemia adjusted to $0.5 \%$ in $1.5 \%$ haematocrit. Each inhibitor was analysed in a three-fold serial dilution in duplicates in three independent experiments and PD was used as a control. Parasite replication was assessed by fluorescent SYBR green staining of parasitic DNA as previously described. ${ }^{64,65}$ After 72 hours, the parasites were frozen at $-80{ }^{\circ} \mathrm{C}$ overnight, followed by thawing and the DNA stained by SYBR green and the fluorescence measured on a plate reader (Promega) at $591 \mathrm{~nm}$ wavelength. For each well, the signal before adding SYBR green was subtracted to the signal with SYBR green to eliminate compound fluorescence. The percentage of surviving parasites compared to controls was determined as follows: $\left(\right.$ Fluo $_{\mathrm{X}}-$ Fluo $\left._{\mathrm{diRBC}}\right) /\left(\right.$ Fluo $_{\mathrm{DMSO}}-$ Fluo $\left._{\mathrm{diRBC}}\right) * 100$ where Fluo $_{\mathrm{X}}$ and Fluo $_{\text {DMSO }}$ are the mean fluorescence signals of parasites incubated with compound X or DMSO as a control, and Fluo ${ }_{\mathrm{diRBC}}$, the mean fluorescence signal of infected parasites exposed to high drug concentrations that kills them all to account for DNA of the starting parasites in each well ( $0.5 \%$ parasitemia). $\mathrm{IC}_{50}$ values were calculated using Prism (GraphPad, log(inhibitor) vs normalized response Variable slope). Control parasitemia at T0 and T72 was determined by microscopic analysis of Giemsa stained blood smears to verify parasite stages and multiplication factor.

\section{ASSOCIATED CONTENT}

\section{Supporting Information}

The Supporting Information is available free of charge at https://pubs.acs.org/doi/10.1021/jacsau.1c00025.

Detailed experimental procedures, spectroscopic data, NMR and mass spectrometry analyses of the new compounds 7-11 and of various partners-probes adducts (PDF)

\section{AUTHOR INFORMATION}

\section{Corresponding Author}

Elisabeth Davioud-Charvet - Université de Strasbourg-CNRS-UHA, UMR7042, Laboratoire d'Innovation Moléculaire et Applications (LIMA), Team Bio(IN)organic and Medicinal Chemistry, European School of Chemistry, Polymers and Materials (ECPM), 67087 Strasbourg, France; (1) orcid.org/0000-0001-7026-4034; Email: elisabeth.davioud@unistra.fr

\section{Authors}

Bogdan Adam Cichocki - Université de Strasbourg-CNRS-UHA, UMR7042, Laboratoire d'Innovation Moléculaire et Applications (LIMA), Team Bio(IN)organic and Medicinal Chemistry, European School of Chemistry, Polymers and Materials (ECPM), 67087 Strasbourg, France

Vrushali Khobragade - Université de Strasbourg-CNRS-UHA, UMR7042, Laboratoire d'Innovation Moléculaire et Applications (LIMA), Team Bio(IN)organic and Medicinal Chemistry, European School of Chemistry, Polymers and Materials (ECPM), 67087 Strasbourg, France

Maxime Donzel - Université de Strasbourg-CNRS-UHA, UMR7042, Laboratoire d'Innovation Moléculaire et Applications (LIMA), Team Bio(IN)organic and Medicinal Chemistry, European School of Chemistry, Polymers and Materials (ECPM), 67087 Strasbourg, France

Leandro Cotos - Université de Strasbourg-CNRS-UHA, UMR7042, Laboratoire d'Innovation Moléculaire et Applications (LIMA), Team Bio(IN)organic and Medicinal Chemistry, European School of Chemistry, Polymers and Materials (ECPM), 67087 Strasbourg, France

Stephanie Blandin - Université de Strasbourg-CNRS-INSERM UPR9022/U1257, Mosquito Immune Responses (MIR), F-67000 Strasbourg, France

Christine Schaeffer-Reiss - Laboratoire de Spectrométrie de Masse BioOrganique, Université Strasbourg, CNRS, IPHC UMR 7178, F-67000 Strasbourg, France

Sarah Cianférani - Laboratoire de Spectrométrie de Masse BioOrganique, Université Strasbourg, CNRS, IPHC UMR 7178, F-67000 Strasbourg, France; 이이.org/00000003-4013-4129

Jean-Marc Strub - Laboratoire de Spectrométrie de Masse BioOrganique, Université Strasbourg, CNRS, IPHC UMR 7178, F-67000 Strasbourg, France

Mourad Elhabiri - Université de Strasbourg-CNRS-UHA, UMR7042, Laboratoire d'Innovation Moléculaire et Applications (LIMA), Team Bio(IN)organic and Medicinal Chemistry, European School of Chemistry, Polymers and Materials (ECPM), 67087 Strasbourg, France; 이이.org/ 0000-0001-6371-7533

Complete contact information is available at: https://pubs.acs.org/10.1021/jacsau.1c00025

\section{Author Contributions}

\#(B.A.C., V.K.) These authors contributed equally

Notes

The authors declare no competing financial interest.

\section{ACKNOWLEDGMENTS}

This work was supported by the French Centre National de la Recherche Scientifique (E.D.-C., M.E. and S.A.B.), the Institut National de la Santé et de la Recherche Médicale (S.A.B.), the University of Strasbourg (E.D.-C., C.S., S.C., J.-M.S., and S.A.B., IDEX grant for the plasmoClick project, postdoctoral salary for B.C.), the French Proteomic Infrastructure (ProFI; ANR-10-INBS-08-03), the Laboratoire d'Excellence (LabEx) ParaFrap (grant LabEx ParaFrap ANR-11-LABX-0024 to E.D.C. and S.A.B., Ph.D. doctoral salary for V.K.), the ANR PRC2017 (grant PlasmoPrim including the salary of the Ph.D. 
student M.D.), the Fondation pour la Recherche en Chimie (grant Innovation for the FluoPlasmo project, postdoctoral salary for L.C.), and the ERC Starting Grant $\mathrm{N}^{\circ} 260918$ (S.A.B.). The authors are indebted to Tobias Müller for preliminary 3-benzoylmenadione 6-nMet photoirradiation experiments, and both master M2 students, Alba Zugasti and Joan Guillem Mayans, for synthetizing the first batch of probes 7 and 11, respectively. They also thank Romain Ruppert (UMR 7177 CNRS-Strasbourg University, Laboratory of Controlled Ligand Architectures in Coordination chemistryCLAC) and Jean-Pierre Sauvage (Institute of Supramolecular Science and Engineering-ISIS, UMR 7006 CNRS-Strasbourg University, Laboratory of Inorganic Chemistry) for fruitful discussion about BCDA solubility, and Alexandre Specht (UMR 7199 CNRS-Strasbourg University, Chemical Biology group) for making available the high-intensity 1000W UV monochromator. Katja Becker (Biochemistry and Molecular Biology, Interdisciplinary Research Centre, Justus Liebig Giessen University) is acknowledged for welcoming V.K. for 2 months in the frame of the COST Action CM1307.

\section{REFERENCES}

(1) Galmozzi, A.; Dominguez, E.; Cravatt, B. F.; Saez, E. Application of Activity-Based Protein Profiling to Study Enzyme Function in Adipocytes. In Methods in Enzymology; Academic Press: San Diego, 2014; pp 151-169.

(2) Whitby, L. R.; Obach, R. S.; Simon, G. M.; Hayward, M. M.; Cravatt, B. F. Quantitative Chemical Proteomic Profiling of the in Vivo Targets of Reactive Drug Metabolites. ACS Chem. Biol. 2017, 12, 2040-2050.

(3) Liu, Y.; Patricelli, M. P.; Cravatt, B. F. Activity-Based Protein Profiling: The Serine Hydrolases. Proc. Natl. Acad. Sci. U. S. A. 1999, 96, 14694-14699.

(4) Yoo, E.; Schulze, C. J.; Stokes, B. H.; Onguka, O.; Yeo, T.; Mok, S.; Gnädig, N. F.; Zhou, Y.; Kurita, K.; Foe, I. T.; Terrell, S. M.; Boucher, M. J.; Cieplak, P.; Kumpornsin, K.; Lee, M. C. S.; Linington, R. G.; Long, J. Z.; Uhlemann, A. C.; Weerapana, E.; Fidock, D. A.; Bogyo, M. The Antimalarial Natural Product Salinipostin A Identifies Essential $\alpha / \beta$ Serine Hydrolases Involved in Lipid Metabolism in P. Falciparum Parasites. Cell Chem. Biol. 2020, 27, 143-157.

(5) Rostovtsev, V. V.; Green, L. G.; Fokin, V. V.; Sharpless, K. B. A Stepwise Huisgen Cycloaddition Process: Copper(I)-Catalyzed Regioselective "Ligation" of Azides and Terminal Alkynes. Angew. Chem., Int. Ed. 2002, 41, 2596-2599.

(6) Lewis, W. G.; Magallon, F. G.; Fokin, V. V.; Finn, M. G. Discovery and Characterization of Catalysts for Azide-Alkyne Cycloaddition by Fluorescence Quenching. J. Am. Chem. Soc. 2004, 126, 9152-9153.

(7) Parker, C. G.; Pratt, M. R. Click Chemistry in Proteomic Investigations. Cell 2020, 180, 605-632.

(8) Wright, A. T.; Song, J. D.; Cravatt, B. F. A Suite of ActivityBased Probes for Human Cytochrome P450 Enzymes. J. Am. Chem. Soc. 2009, 131, 10692-10700.

(9) Rotili, D.; Altun, M.; Kawamura, A.; Wolf, A.; Fischer, R.; Leung, I. K. H.; MacKeen, M. M.; Tian, Y. M.; Ratcliffe, P. J.; Mai, A.; Kessler, B. M.; Schofield, C. J. A Photoreactive Small-Molecule Probe for 2-Oxoglutarate Oxygenases. Chem. Biol. 2011, 18, 642-654.

(10) Burke, A. A.; Barrows, L.; Solares, M. J.; Wall, A. D.; Jakobsche, C. E. Bifunctional Molecular Probes for Activity-Based Visualization of Quinone-Dependent Amine Oxidases. Chem. - Eur. J. 2018, 24, 17681-17685.

(11) Krysiak, J. M.; Kreuzer, J.; Macheroux, P.; Hermetter, A.; Sieber, S. A.; Breinbauer, R. Activity-Based Probes for Studying the Activity of Flavin-Dependent Oxidases and for the Protein Target Profiling of Monoamine Oxidase Inhibitors. Angew. Chem., Int. Ed. 2012, 51, 7035-7040.
(12) Penarete-Vargas, D. M.; Boisson, A.; Urbach, S.; Chantelauze, H.; Peyrottes, S.; Fraisse, L.; Vial, H. J. A Chemical Proteomics Approach for the Search of Pharmacological Targets of the Antimalarial Clinical Candidate Albitiazolium in Plasmodium Falciparum Using Photocrosslinking and Click Chemistry. PLoS One 2014, 9, No. e113918.

(13) Wright, M. H.; Clough, B.; Rackham, M. D.; Rangachari, K.; Brannigan, J. A.; Grainger, M.; Moss, D. K.; Bottrill, A. R.; Heal, W. P.; Broncel, M.; Serwa, R. A.; Brady, D.; Mann, D. J.; Leatherbarrow, R. J.; Tewari, R.; Wilkinson, A. J.; Holder, A. A.; Tate, E. W. Validation of N-Myristoyltransferase as an Antimalarial Drug Target Using an Integrated Chemical Biology Approach. Nat. Chem. 2014, 6, $112-121$.

(14) Wang, J.; Zhang, C. J.; Chia, W. N.; Loh, C. C. Y.; Li, Z.; Lee, Y. M.; He, Y.; Yuan, L. X.; Lim, T. K.; Liu, M.; Liew, C. X.; Lee, Y. Q.; Zhang, J.; Lu, N.; Lim, C. T.; Hua, Z. C.; Liu, B.; Shen, H. M.; Tan, K. S. W.; Lin, Q. Haem-Activated Promiscuous Targeting of Artemisinin in Plasmodium Falciparum. Nat. Commun. 2015, 6, 10111.

(15) Ismail, H. M.; Barton, V. E.; Panchana, M.; Charoensutthivarakul, S.; Biagini, G. A.; Ward, S. A.; O’Neill, P. M. Corrigendum: A Click Chemistry-Based Proteomic Approach Reveals That 1,2,4-Trioxolane and Artemisinin Antimalarials Share a Common Protein Alkylation Profile. Angew. Chem., Int. Ed. 2016, $55,10548$.

(16) Lubin, A. S.; Rueda-Zubiaurre, A.; Matthews, H.; Baumann, H.; Fisher, F. R.; Morales-Sanfrutos, J.; Hadavizadeh, K. S.; Nardella, F.; Tate, E. W.; Baum, J.; Scherf, A.; Fuchter, M. J. Development of a Photo-Cross-Linkable Diaminoquinazoline Inhibitor for Target Identification in Plasmodium Falciparum. ACS Infect. Dis. 2018, 4, 523-530.

(17) Müller, T.; Johann, L.; Jannack, B.; Brückner, M.; Lanfranchi, D. A.; Bauer, H.; Sanchez, C.; Yardley, V.; Deregnaucourt, C.; Schrével, J.; Lanzer, M.; Schirmer, R. H.; Davioud-Charvet, E. Glutathione Reductase-Catalyzed Cascade of Redox Reactions to Bioactivate Potent Antimalarial 1,4-Naphthoquinones-a New Strategy to Combat Malarial Parasites. J. Am. Chem. Soc. 2011, 133, 1155711571.

(18) Bauer, H.; Fritz-Wolf, K.; Winzer, A.; Kühner, S.; Little, S.; Yardley, V.; Vezin, H.; Palfey, B.; Schirmer, R. H.; Davioud-Charvet, E. A Fluoro Analogue of the Menadione Derivative 6-[2'-(3'-Methyl) $-1^{\prime}, 4^{\prime}$-Naphthoquinolyl]Hexanoic Acid Is a Suicide Substrate of Glutathione Reductase. Crystal Structure of the Alkylated Human Enzyme. J. Am. Chem. Soc. 2006, 128, 10784-10794.

(19) Sidorov, P.; Desta, I.; Chessé, M.; Horvath, D.; Marcou, G.; Varnek, A.; Davioud-Charvet, E.; Elhabiri, M. Redox Polypharmacology as an Emerging Strategy to Combat Malarial Parasites. ChemMedChem 2016, 11, 1339-1351.

(20) Bielitza, M.; Belorgey, D.; Ehrhardt, K.; Johann, L.; Lanfranchi, D. A.; Gallo, V.; Schwarzer, E.; Mohring, F.; Jortzik, E.; Williams, D. L.; Becker, K.; Arese, P.; Elhabiri, M.; Davioud-Charvet, E. Antimalarial NADPH-Consuming Redox-Cyclers as Superior Glucose-6-Phosphate Dehydrogenase Deficiency Copycats. Antioxid. Redox Signaling 2015, 22, 1337-1351.

(21) Feng, L.; Lanfranchi, D. A.; Cotos, L.; Cesar-Rodo, E.; Ehrhardt, K.; Goetz, A. A.; Zimmermann, H.; Fenaille, F.; Blandin, S. A.; Davioud-Charvet, E. Synthesis of Plasmodione Metabolites and 13C-Enriched Plasmodione as Chemical Tools for Drug Metabolism Investigation. Org. Biomol. Chem. 2018, 16, 2647-2665.

(22) Mounkoro, P.; Michel, T.; Blandin, S.; Golinelli-Cohen, M. P.; Davioud-Charvet, E.; Meunier, B. Investigating the Mode of Action of the Redox-Active Antimalarial Drug Plasmodione Using the Yeast Model. Free Radical Biol. Med. 2019, 141, 269-278.

(23) Oelgemöller, M.; Schiel, C.; Fröhlich, R.; Mattay, J. The "Photo-Friedel-Crafts Acylation" of 1,4-Naphthoquinones. Eur. J. Org. Chem. 2002, 2002, 2465.

(24) Deseke, E.; Nakatani, Y.; Ourisson, G. Intrinsic Reactivities of Amino Acids towards Photoalkylation with Benzophenone - A Study Preliminary to Photolabelling of the Transmembrane Protein Glycophorin A. Eur. J. Org. Chem. 1998, 1998, 243-251. 
(25) Wittelsberger, A.; Thomas, B. E.; Mierke, D. F.; Rosenblatt, M. Methionine Acts as a "Magnet" in Photoaffinity Crosslinking Experiments. FEBS Lett. 2006, 580, 1872-1876.

(26) Mitchell, L. J.; Lewis, W.; Moody, C. J. Solar Photochemistry: Optimisation of the Photo Friedel-Crafts Acylation of Naphthoquinones. Green Chem. 2013, 15, 2830-2842.

(27) Hansch, C.; Leo, A.; Taft, R. W. A Survey of Hammett Substituent Constants and Resonance and Field Parameters. Chem. Rev. 1991, 91, 165-195.

(28) Cosa, G. Photodegradation and Photosensitization in Pharmaceutical Products: Assessing Drug Phototoxicity. In Pure Appl. Chem.; Walter de Gruyter GmbH, 2004; Vol. 76, pp 263-275. (29) Bizier, N. P.; Wackerly, J. W.; Braunstein, E. D.; Zhang, M.; Nodder, S. T.; Carlin, S. M.; Katz, J. L. An Alternative Role for Acetylenes: Activation of Fluorobenzenes toward Nucleophilic Aromatic Substitution. J. Org. Chem. 2013, 78, 5987-5998.

(30) Chen, Y.; Wu, Y.; Henklein, P.; Li, X.; Hofmann, K. P.; Nakanishi, K.; Ernst, O. P. A Photo-Cross-Linking Strategy to Map Sites of Protein-Protein Interactions. Chem. - Eur. J. 2010, 16, 73897394.

(31) Cotos, L.; Donzel, M.; Elhabiri, M.; Davioud-Charvet, E. Cover Feature: A Mild and Versatile Friedel-Crafts Methodology for the Diversity-Oriented Synthesis of Redox-Active 3-Benzoylmenadiones with Tunable Redox Potentials (Chem. Eur. J. 15/2020). Chem. - Eur. J. 2020, 26, 3192-3192.

(32) Anderson, J. M.; Kochi, J. K. Silver (I)-Catalyzed Oxidative Decarboxylation of Acids by Peroxydisulfate. the Role of Silver (II). J. Am. Chem. Soc. 1970, 92, 1651-1659.

(33) Salmon-Chemin, L.; Buisine, E.; Yardley, V.; Kohler, S.; Debreu, M. A.; Landry, V.; Sergheraert, C.; Croft, S. L.; Krauth-Siegel, R. L.; Davioud-Charvet, E. 2- and 3-Substituted 1,4-Naphthoquinone Derivatives as Subversive Substrates of Trypanothione Reductase and Lipoamide Dehydrogenase from Trypanosoma Cruzi: Synthesis and Correlation between Redox Cycling Activities and in Vitro Cytotoxicity. J. Med. Chem. 2001, 44, 548-565.

(34) Karplus, P. A.; Pai, E. F.; Schulz, G. E. A Crystallographic Study of the Glutathione Binding Site of Glutathione Reductase at 0.3-nm Resolution. Eur. J. Biochem. 1989, 178, 693-703.

(35) Görner, H. Photoreduction of Nitro-1,4-Naphthoquinones in Solution. J. Photochem. Photobiol., A 2011, 224, 135-140.

(36) Bao, K.; Li, F.; Liu, H.; Wang, Z.; Shen, Q.; Wang, J.; Zhang, W. Activated Carbon for Aerobic Oxidation: Benign Approach toward 2-Benzoylbenzimidazoles and 2-Benzoylbenzoxazoles Synthesis. Sci. Rep. 2015, 5, 10360.

(37) Blair, D.; Diehl, H. Bathophenanthrolinedisulphonic Acid and Bathocuproinedisulphonic Acid, Water Soluble Reagents for Iron and Copper. Talanta 1961, 7, 163-174.

(38) Hong, V.; Udit, A. K.; Evans, R. A.; Finn, M. G. Electrochemically Protected Copper(I)-Catalyzed Azide-Alkyne Cycloaddition. ChemBioChem 2008, 9, 1481-1486.

(39) Moutiez, M.; Quéméneur, E.; Sergheraert, C.; Lucas, V.; Tartar, A.; Davioud-Charvet, E. Glutathione-Dependent Activities of Trypanosoma Cruzi P52 Makes It a New Member of the Thiol:Disulphide Oxidoreductase Family. Biochem. J. 1997, 322, 43-48.

(40) Ando, Y.; Suzuki, K. Photoredox Reactions of Quinones. Chem.-Eur. J.; Wiley-VCH Verlag October 26, 2018; pp 1595515964.

(41) Ando, Y.; Matsumoto, T.; Suzuki, K. Intramolecular Photoredox Reaction of Naphthoquinone Derivatives. Synlett 2017, 28, $1040-1045$.

(42) Porhun, V. I.; Rakhimov, A. I. Mechanism of the Photochemical Reactions of Substituted Benzoquinones. Russ. J. Gen. Chem. 2011, 81, 890-912.

(43) Belin, C.; Béarnais-Barbry, S.; Bonneau, R. Mechanism of Photocyclization of Substituted Phenylbenzoquinones. J. Photochem. Photobiol., A 2001, 139, 111-124.

(44) Marquardt, R.; Grandjean, S.; Bonneau, R. Competition between Intersystem Crossing and Intramolecular Electron Transfer in Substituted Benzoquinones. J. Photochem. Photobiol., A 1992, 69, 143-153.

(45) Hacker, S. M.; Backus, K. M.; Lazear, M. R.; Forli, S.; Correia, B. E.; Cravatt, B. F. Global Profiling of Lysine Reactivity and Ligandability in the Human Proteome. Nat. Chem. 2017, 9, 11811190.

(46) Savvides, S. N.; Karplus, P. A. Kinetics and Crystallographic Analysis of Human Glutathione Reductase in Complex with a Xanthene Inhibitor. J. Biol. Chem. 1996, 271, 8101-8107.

(47) Schönleben-Janas, A.; Kirsch, P.; Mittl, P. R. E.; Schirmer, R. H.; Krauth-Siegel, R. L. Inhibition of Human Glutathione Reductase by 10-Arylisoalloxazines: Crystallographic, Kinetic, and Electrochemical Studies. J. Med. Chem. 1996, 39, 1549-1554.

(48) Krauth-Siegel, R. L.; Arscott, L. D.; Schönleben-Janas, A.; Schirmer, R. H.; Williams, C. H. Role of Active Site Tyrosine Residues in Catalysis by Human Glutathione Reductase. Biochemistry 1998, 37, 13968-13977.

(49) Sarma, G. N.; Savvides, S. N.; Becker, K.; Schirmer, M.; Schirmer, R. H.; Karplus, P. A. Glutathione Reductase of the Malarial Parasite Plasmodium Falciparum: Crystal Structure and Inhibitor Development. J. Mol. Biol. 2003, 328, 893-907.

(50) Berkholz, D. S.; Faber, H. R.; Savvides, S. N.; Karplus, P. A. Catalytic Cycle of Human Glutathione Reductase Near $1 \AA$ Resolution. J. Mol. Biol. 2008, 382, 371-384.

(51) Muñoz-Durango, K.; Maciuk, A.; Harfouche, A.; TorijanoGutiérrez, S.; Jullian, J. C.; Quintin, J.; Spelman, K.; Mouray, E.; Grellier, P.; Figadère, B. Detection, Characterization, and Screening of Heme-Binding Molecules by Mass Spectrometry for Malaria Drug Discovery. Anal. Chem. 2012, 84, 3324-3329.

(52) Xu Kelly, J.; Winter, R.; Riscoe, M.; Peyton, D. H. A Spectroscopic Investigation of the Binding Interactions between 4,5Dihydroxyxanthone and Heme. J. Inorg. Biochem. 2001, 86, 617-625.

(53) Bunte, J. O.; Heilmann, E. K.; Hein, B.; Mattay, J. Cyclizations of Silyl Enol Ether Radical Cations- The Cause of the Stereoselectivity. Eur. J. Org. Chem. 2004, 2004, 3535-3550.

(54) Robert, A.; Benoit-Vical, F.; Claparols, C.; Meunier, B. The Antimalarial Drug Artemisinin Alkylates Heme in Infected Mice. Proc. Natl. Acad. Sci. U. S. A. 2005, 102, 13676-13680.

(55) Winter, R. W.; Cornell, K. A.; Johnson, L. L.; Ignatushchenko, M.; Hinrichs, D. J.; Riscoe, M. K. Potentiation of the Antimalarial Agent Rufigallol. Antimicrob. Agents Chemother. 1996, 40, 1408-1411.

(56) Winter, R. W.; Ignatushchenko, M.; Ogundahunsi, O. A. T.; Cornell, K. A.; Oduola, A. M. J.; Hinrichs, D. J.; Riscoe, M. K. Potentiation of an Antimalarial Oxidant Drug. Antimicrob. Agents Chemother. 1997, 41, 1449-1454.

(57) Mounkoro, P.; Michel, T.; Golinelli-Cohen, M. P.; Blandin, S.; Davioud-Charvet, E.; Meunier, B. A Role for the Succinate Dehydrogenase in the Mode of Action of the Redox-Active Antimalarial Drug, Plasmodione. Free Radical Biol. Med. 2021, 162, $533-541$.

(58) Gross, J. H.; Nieth, N.; Linden, H. B.; Blumbach, U.; Richter, F. J.; Tauchert, M. E.; Tompers, R.; Hofmann, P. Liquid Injection Field Desorption/Ionization of Reactive Transition Metal Complexes. Anal. Bioanal. Chem. 2006, 386, 52-58.

(59) Simpson, R. J. Staining Proteins in Gels with Coomassie Blue. Cold Spring Harb. Protoc. 2007, 2007, pdb.prot4697.

(60) Pettersen, E. F.; Goddard, T. D.; Huang, C. C.; Couch, G. S.; Greenblatt, D. M.; Meng, E. C.; Ferrin, T. E. UCSF Chimera - A Visualization System for Exploratory Research and Analysis. J. Comput. Chem. 2004, 25, 1605-1612.

(61) Mishra, E.; Worlinsky, J. L.; Gilbert, T. M.; Brückner, C.; Ryzhov, V. Erratum: Axial Imidazole Binding Strengths in Porphyrinoid Cobalt(III) Complexes as Studied by Tandem Mass Spectrometry. J. Am. Soc. Mass Spectrom. 2012, 23, 1428-1439.

(62) Witkowski, B.; Amaratunga, C.; Khim, N.; Sreng, S.; Chim, P.; Kim, S.; Lim, P.; Mao, S.; Sopha, C.; Sam, B.; Anderson, J. M.; Duong, S.; Chuor, C. M.; Taylor, W. R.; Suon, S.; MercereauPuijalon, O.; Fairhurst, R. M.; Menard, D. Novel Phenotypic Assays for the Detection of Artemisinin-Resistant Plasmodium Falciparum 
Malaria in Cambodia: In-Vitro and Ex-Vivo Drug-Response Studies. Lancet Infect. Dis. 2013, 13, 1043-1049.

(63) Ariey, F.; Witkowski, B.; Amaratunga, C.; Beghain, J.; Langlois, A. C.; Khim, N.; Kim, S.; Duru, V.; Bouchier, C.; Ma, L.; Lim, P.; Leang, R.; Duong, S.; Sreng, S.; Suon, S.; Chuor, C. M.; Bout, D. M.; Ménard, S.; Rogers, W. O.; Genton, B.; Fandeur, T.; Miotto, O.; Ringwald, P.; Le Bras, J.; Berry, A.; Barale, J. C.; Fairhurst, R. M.; Benoit-Vical, F.; Mercereau-Puijalon, O.; Ménard, D. A Molecular Marker of Artemisinin-Resistant Plasmodium Falciparum Malaria. Nature 2014, 505, 50-55.

(64) Beez, D.; Sanchez, C. P.; Stein, W. D.; Lanzer, M. Genetic Predisposition Favors the Acquisition of Stable Artemisinin Resistance in Malaria Parasites. Antimicrob. Agents Chemother. 2011, $55,50-55$.

(65) Smilkstein, M.; Sriwilaijaroen, N.; Kelly, J. X.; Wilairat, P.; Riscoe, M. Simple and Inexpensive Fluorescence-Based Technique for High-Throughput Antimalarial Drug Screening. Antimicrob. Agents Chemother. 2004, 48, 1803-1806. 